NBER WORKING PAPER SERIES

\title{
AFTER MIDNIGHT: A REGRESSION DISCONTINUITY DESIGN IN LENGTH OF POSTPARTUM HOSPITAL STAYS
}

\author{
Douglas Almond \\ Joseph J. Doyle, Jr. \\ Working Paper 13877 \\ http://www.nber.org/papers/w13877
NATIONAL BUREAU OF ECONOMIC RESEARCH
1050 Massachusetts Avenue
Cambridge, MA 02138
March 2008

Josh Angrist, Janet Currie, Carlos Dobkin, Randall Ellis, Michael Greenstone, Rick Hornbeck, David Lee, Doug Miller, Roberto Rigobon, Jon Skinner, Tom Stoker, and Tavneet Suri provided helpful comments and discussions. We also thank Jan Morgan of the California Healthcare Information Resource Center for helpful advice and discussions, Nicole Radmore for help with the National Hospital Discharge Survey data, and Sammy Burfeind, whose birth inspired our empirical approach. The views expressed herein are those of the author(s) and do not necessarily reflect the views of the National Bureau of Economic Research.

NBER working papers are circulated for discussion and comment purposes. They have not been peerreviewed or been subject to the review by the NBER Board of Directors that accompanies official NBER publications.

(C) 2008 by Douglas Almond and Joseph J. Doyle, Jr.. All rights reserved. Short sections of text, not to exceed two paragraphs, may be quoted without explicit permission provided that full credit, including (C) notice, is given to the source. 
NBER WORKING PAPER SERIES

\title{
AFTER MIDNIGHT: A REGRESSION DISCONTINUITY DESIGN IN LENGTH OF POSTPARTUM HOSPITAL STAYS
}

\author{
Douglas Almond \\ Joseph J. Doyle, Jr. \\ Working Paper 13877 \\ http://www.nber.org/papers/w13877
NATIONAL BUREAU OF ECONOMIC RESEARCH
1050 Massachusetts Avenue
Cambridge, MA 02138
March 2008

Josh Angrist, Janet Currie, Carlos Dobkin, Randall Ellis, Michael Greenstone, Rick Hornbeck, David Lee, Doug Miller, Roberto Rigobon, Jon Skinner, Tom Stoker, and Tavneet Suri provided helpful comments and discussions. We also thank Jan Morgan of the California Healthcare Information Resource Center for helpful advice and discussions, Nicole Radmore for help with the National Hospital Discharge Survey data, and Sammy Burfeind, whose birth inspired our empirical approach. The views expressed herein are those of the author(s) and do not necessarily reflect the views of the National Bureau of Economic Research.

(C) 2008 by Douglas Almond and Joseph J. Doyle, Jr.. All rights reserved. Short sections of text, not to exceed two paragraphs, may be quoted without explicit permission provided that full credit, including (c) notice, is given to the source. 
After Midnight: A Regression Discontinuity Design in Length of Postpartum Hospital Stays Douglas Almond and Joseph J. Doyle, Jr.

NBER Working Paper No. 13877

March 2008

JEL No. H51,I11,I12,J13

\begin{abstract}
$\underline{\text { ABSTRACT }}$
Patients who receive more hospital treatment tend to have worse underlying health, confounding estimates of the returns to such care. This paper compares the costs and benefits of extending the length of hospital stay following delivery using a discontinuity in stay length for infants born close to midnight. Third-party reimbursement rules in California entitle newborns to a minimum number of hospital "days," counted as the number of midnights in care. A newborn delivered at 12:05 a.m. will have an extra night of reimbursable care compared to an infant born minutes earlier. We use a dataset of all California births from 1991-2002, including nearly 100,000 births within 20 minutes of midnight, and find that children born just prior to midnight have significantly shorter lengths of stay than those born just after midnight, despite similar observable characteristics. Furthermore, a law change in 1997 entitled newborns to a minimum of 2 days in care. The midnight discontinuity can therefore be used to consider two distinct treatments: increasing stay length from one to two nights (prior to the law change) and from two to three nights (following the law change). On both margins, we find no effect of stay length on readmissions or mortality for either the infant or the mother, and the estimates are precise. The results suggest that for uncomplicated births, longer hospitals stays incur substantial costs without apparent health benefits.
\end{abstract}

\author{
Douglas Almond \\ Department of Economics \\ Columbia University \\ International Affairs Building, MC 3308 \\ 420 West 118th Street \\ New York, NY 10027 \\ and NBER \\ da2152@columbia.edu \\ Joseph J. Doyle, Jr. \\ MIT Sloan School of Management \\ 50 Memorial Drive \\ E52-447 \\ Cambridge, MA 02142 \\ and NBER \\ jjdoyle@mit.edu
}




\section{Introduction}

The amount of time spent in hospital after childbirth has changed substantially over the last generation. Between 1970 and 1995, the average length of stay fell from 4.1 to 2.1 days (Figure 1). Increased cesarean deliveries over this same period masks even larger decreases in stay length conditional on method of delivery [9]. By the early 1990s, third-party payers routinely declined coverage of hospital stays longer than 24 hours for uncomplicated vaginal deliveries [1].

The shift toward shorter postpartum stays was controversial and politically unpopular. Between 1995 and 1998, 42 states passed laws requiring insurers to cover minimum postpartum lengths of stay [11]. In January 1998, the federal government followed suit, mandating a minimum stay of 2 days. The average length of hospital stay for mothers increased $20 \%$ between 1995 and 1998, and newborns' stays increased from 2.8 days to $3.2[20]$. The fraction of vaginal deliveries with stay lengths under two days fell by half - from $47 \%$ in 1995 to $23 \%$ in 1998 (Figure 2).

As delivery is one of the most commonly performed surgical procedure in the U.S., secular changes in stay length have significant implications for health care costs and health outcomes. ${ }^{1}$ Studies of the law changes themselves, however, have yielded mixed evidence. For example, Evans et al. [11] found that California's law improved health outcomes for vagi-

\footnotetext{
${ }^{1}$ Delivery is the most commonly performed surgical procedure in our analysis period. Since 2002, operations involving the cardiovascular system have been more frequently performed than obstetrical procedures (NCHS [20] and various additional years).
} 
nal deliveries in the Medicaid population, but not for privately-insured patients. Implementation of the law was not immediate, and time-series comparisons yield unbiased estimates of the health impact to the extent that other health determinants did not happen to change over the implementation period.

Our approach departs from previous work by comparing infants born at nearly the same point in time. We use the fact that billing rules reimburse hospitals based on the number of days the newborn is in the hospital. These days are counted as the number of midnights in care. A newborn delivered at 12:05 a.m. will have nearly a full day in care before being "logged" as present in the hospital, whereas a newborn delivered at 11:55 p.m. will be counted as present only 5 minutes after delivery. As a result, those born just after midnight have an extra night of reimbursable care compared to those born just prior to midnight.

The analysis uses hospital discharge data linked to birth and death certificates for all births in California from 1991 to 2002. These data report the hour and minute of birth. An additional dimension of our empirical analysis is made possible by the 1997 Newborns' and Mothers' Health Act: a law in California that mandates insurance coverage for a minimum of 2 days in hospital. This allows us to trace out the effect of an increase in stay length using the midnight discontinuity from two different baselines. Prior to the law, the midnight threshold primarily induced variation between 0 and 1 additional midnights (i.e. one versus two total nights in the hospital). Following the law, the midnight threshold primarily induced patients to 
switch between 1 and 2 additional midnights (or two versus three total nights in hospital). Thus, we can use the midnight rule to evaluate the effect of a two-day minimum stay dictated by law (and recommended by the American Academy of Pediatrics) compared to a further expansion in length of stay from two to three nights.

We find that the difference in privately-born costs associated with the minute of birth generates a substantial difference in average stay length, despite nearly identical observable characteristics. Infants born shortly after midnight spend an additional 0.25 nights in the hospital - a difference similar to the change in length of stay when the California mandate increased the minimum stay by one day.

Despite the longer stays for infants born after midnight, we find no effect of a post-midnight birth on health outcomes. Both visual inspections of the raw data and models that control for patient characteristics reveal estimates close to zero for hospital readmissions and infant mortality. Given that these follow-up expenses were covered by insurance companies, the push toward shorter lengths of stay in the early 1990s presumably reduced costs for insurers.

The results apply to a population that is induced to have a longer hospital stay as a result of a post-midnight birth. A priori, these are likely uncomplicated cases where the minute of birth is plausibly exogenous and the stays are not expected to be especially long - patients in a part of the health distribution where the minimum stay legislation may be most likely to bind. While these "compliers" cannot be identified in the data, 
we estimate their mean characteristics. As expected, compliers are less likely to be low birthweight and more likely to be full term compared to the full population. Furthermore, larger effects of a post-midnight birth on length of stay are found for those more likely to have benefitted from it - particularly prior to the 1997 law, when average stay lengths were shorter. Among mothers covered by Medicaid, for example, the increase in stay length for births after midnight was approximately $40 \%$ longer than the post-midnight increase among non-Medicaid births. Nevertheless, no health outcome differences were detected within this population.

The rest of the paper is organized as follows. Section 2 considers the background that led to early discharge laws and the role that minute of birth plays in determining the length of stay. Section 3 describes the data. Section 4 describes the model and estimation, describing the manner in which we trace out the effects of length of stay from 0 to 1 and from 1 to 2 additional nights in care. Section 5 presents the results and section 6 interprets the results in comparison to the costs of an additional night in care. Section 7 concludes.

\section{Background}

Between 1970 and 1995, the average length of stay for a vaginal delivery fell from 3.9 to 1.7 days (Figure 1). For cesarean births, the corresponding numbers are 7.8 to 3.6 days [9]. In the mid-1990s, this decrease was halted, and if anything slight increases in average stays followed. ${ }^{2}$ For short-

\footnotetext{
${ }^{2}$ NCHS [20] and various additional years.
} 
stays, the pattern is more stark. Figure 2 plots the share of vaginal births with stays under 2 days from 1970-2004. There is a doubling of these "early discharges" from 1990 to 1995, followed by a sharp and sustained reduction.

The practice of "drive-through delivery" formed a rallying point against cost-saving measures imposed by third-party payers [13]. In 1995, the official journal of the American Academy of Pediatrics ran a commentary entitled: "Early discharge, in the end: maternal abuse, child neglect, and physician harassment," 3 that warned inadequate screening of newborns was the "most dangerous and potentially long-term effect of early discharge." In particular, early discharge had caused the "re-emergence" of jaundice as a cause of hospital re-admission [6]. In 2005, the American Academy of Pediatrics published criteria for the discharge of newborns, noting it is "unlikely that fulfillment of these criteria and conditions can be accomplished in 48 hours" even for healthy newborns [1].

On August 26, 1997 the California Newborns' and Mothers' Health Act came into effect in California that entitled newborns to 48 hours of inpatient care, as well as coverage for early follow-up care if the newborn is discharged early. A federal law would come into existence the following year. Figure 3 shows that the fraction of vaginal births in California that had an early discharge increased to $75 \%$ prior to the law change, and decreased from October 1997 to February 1998 to $50 \% .^{4}$

\footnotetext{
${ }^{3}$ As noted by Hyman [13].

${ }^{4}$ The spikes seen represent December 24 each year when short stays are particularly common.
} 


\subsection{Minimum Length of Stay Laws}

Previous work comparing newborns born just before and after such law changes have consistently found that the laws increased stay lengths. Findings for health impacts, however, have been mixed.

Meara et al. [18] studied newborns covered by the Medicaid program in Ohio from 1991-1998. Using an interrupted time-series design, they found "modest reductions" in readmissions for jaundice and emergency department visits following the introduction of minimum-stay legislation in 1996. All-cause rehospitalization, as well as readmissions for dehydration and infection, were not found to be affected by the law change.

Madden et al. [15] analyzed newborn health outcomes in a Massachusetts HMO before and after implementation of the state's early discharge law in February 1996. They found longer stay lengths, but no effects on emergency department visits or re-hospitalizations. However, at the end of 1994 the HMO initiated a program for deliveries that included "increased prenatal participation" and a home visit by a nurse within 48 hours of discharge[15]. This program was discontinued when the state discharge law came in to effect.

Evans et al. [11] also use a time-series design to analyze the impact of California's minimum stay law, passed and enacted in August 1997. The law mandated that insurance cover at least two days in the hospital or an early follow-up visit in a physician's office or at home. Between August 1997 and January of 1998, when the federal early-discharge law came in to effect, the fraction of newborns discharged "early" fell sharply (Figure 3). 
Like Meara et al. [18], Evans et al. [11] find decreases in readmission rates for the Medicaid population with vaginal deliveries. Evans et al. [11] also find some improvements in outcomes for privately-insured vaginal births that exhibited some complications following the early discharge law.

Several recent papers have emphasized the persistence of health complications related to early discharge despite implementation of laws mandating coverage of minimum hospital stays. Noting that early discharge is not precluded under the federal early discharge law, Galbraith et al. [12] found that $49.4 \%$ of their sample of California births in 1999 were discharged "early", i.e. prior to the expiration of insurance coverage. ${ }^{5}$ Deliveries paid for by Medicaid or where the mother was Hispanic were more likely to be discharged early. Galbraith et al. [12] concluded that: "issuance of professional guidelines and legislation alone cannot ensure adequate postnatal services, particularly among the groups of socioeconomically vulnerable newborns." Similarly, Paul et al. [21] argued that "well-intentioned [early discharge] legislation and current practice may not be sufficiently protecting the health of newborns."

In an attempt to buffer the presumed effects of early discharge that occurred despite the legislation, early follow-up visits were mandated in these cases. Previous evidence suggests that such a mandate is unlikely to affect the take up of such services, however. Meara et al. [18] find no effect of Ohio minimum stay-early follow-up visit legislation on the take up of

\footnotetext{
${ }^{5}$ And as defined by the American College of Obstetricians: under 48 hours for vaginal deliveries and under 96 ours for cesarian births [12].
} 
early follow-up care among the state's Medicaid population, and Galbraith et al. [12] find no difference in early follow-up care for newborns who were discharged early versus those who were not. These results suggest that our comparisons of effects before and the California law are unlikely to be affected by differences in early follow-up care.

The identifying assumption underlying the interrupted time-series approach is that the trend in length of stay and outcomes prior to the law change describes the counterfactual length of stay and outcomes after the law change. If other interventions happened at the same time as the law change, then the before-after effects may reflect both the law change and the complementary interventions. For example, if the policy change was accompanied by warnings of the increase in jaundice in the early 1990s, then policies that aimed to reduce jaundice infections may have happened at the same time as the extended stays. If hospitals began responding to public criticism prior to the enactment, or if the law imposed shortrun costs on hospitals, then the change in outcomes before and after the law will measure the effect of the change in length of stay as well as the response to the law. ${ }^{6}$

\footnotetext{
${ }^{6}$ Our analysis of California data finds that the daily number of newborns in the hospital increased by approximately 10\% between June 1997 and August 1998 in California. Treatment choices do not appear to change at the time of the law, although there is suggestive evidence that cesarean section rates increased beginning in January 1998; they were close to $21 \%$ for 3 years prior to the federal mandate, increased to $22 \%$ in March 1998, and continued to increase to $27 \%$ by the end of the sample period (2002).
} 


\subsection{Time of Birth and Stay Length}

Length of stay is typically measured as the number of midnights spent in hospital. For postpartum stays, care is generally reimbursed for a predetermined number of midnights in care, with longer stays requiring physician approval. For example, the Medicaid program in California, known as "Medi-Cal", issues the following guidelines regarding prior authorization for obstetric admissions:

Welfare and Institutions Code, Section 14132.42, mandates that a minimum of 48 hours of inpatient hospital care following a normal vaginal delivery and 96 hours following a delivery by cesarean section are reimbursable without prior authorization. For [Treatment Authorization Requests (TARs)] and claims processing purposes, it is necessary to use calendar days instead of hours to implement these requirements. Therefore, a maximum of two consecutive days following a vaginal delivery or four consecutive days following a delivery by cesarean section is reimbursable, without a Treatment Authorization Request. The post-delivery TAR-free period begins at midnight after the mother delivers. [19]

For a birth occurring at 11:59 p.m., the number of reimbursable days in care begins one minute later, whereas births just after midnight are afforded nearly a full 24-hour period before the number of reimbursable days in care begin to be counted. 
An underlying assumption is that for uncomplicated deliveries, the actual minute of birth around midnight is effectively random. There are ways of increasing or decreasing the speed of the delivery, however, and physician may have some discretion over the recording of the time of the delivery. In terms of incentives, the patient and the insurer would prefer a post-midnight birth, as billing for time in the hospital would not begin until one day later. The hospital would likely prefer a pre-midnight birth to begin billing for the time in care sooner. The cost to the hospital of supervising the child would also decline if the birth occurred before midnight and the discharge time was sooner. To the extent that the physician's interest is aligned with the patient (or the insurer), there may be a tendency to record births after midnight, whereas if the incentives are aligned with the hospital, the tendency would be to record births just before midnight. We will consider the frequency of births around midnight for all births, as well as births that occur in Kaiser Hospitals-hospitals where the insurer owns the hospital.

If the birth occurs after midnight, the family effectively has a property right to the hospital bed for one additional night. In a setting of costless bargaining, this increase in the property right might not be expected to have any impact on stay length [8]. If the insurer wanted to bargain for shorter stay lengths, however, they would face political costs. Before the minimum stay law, policy and practice entitled newborns to only 1 day in the hospital. After the law change, insurers are limited to the use the early follow-up care as an incentive for an early discharge, although 
previous evidence suggests that early follow-up visits are not determined by length of stay.

Previous work most closely related to our approach is Malkin et al. [16]. They used 4-hour categories in the time of birth as an instrument for length of stay. They found significant reductions in newborn readmissions with longer postpartum hospital stays. However, births scheduled for "business hours" may have different baseline characteristics compared to births later in the day (reflecting, e.g., the scheduling of high-risk deliveries). Indeed, in California, we find that baseline health and demographic characteristics are on average different during "business hours" compared to the overnight hours. ${ }^{7}$ For this reason, we will restrict comparisons to births just before and after midnight when observable characteristics are similar across the newborns.

\footnotetext{
${ }^{7}$ As in Malkin (2000) we find infants born between 8 a.m. and 12 noon have a length of stay that is 7 hours longer than those born between 8 p.m. and 12 midnight (discharge time was assumed to be 5 p.m. for those with same day discharges and 1 p.m. for those who stay at least one night in the hospital). We also find statistically significant decreases in readmissions with an increase in length of stay using these 4hour blocks as instruments. The groups differ substantially, however, with the largest differences found for mother's first birth (34\% for morning births vs. $44 \%$ for 8 -midnight births), induced labor (only $6 \%$ for 8 a.m. to noon vs. $12 \%$ for those occurring later in the evening), and cesarean section (30\% vs. $14 \%$ for those born between 8 a.m. and noon vs. midnight to 4 a.m.).
} 


\section{Data}

\subsection{Description}

Our data include the universe of live births in California from 1991-2002, some 6.6 million records. We focus on the 270,000 births occurring between 11 p.m. and 1 a.m. The California Office of Statewide Health Planning and Development created a research database that includes hospital discharge records linked to birth and death certificate records. For a given birth, discharge data are available nine months prior to delivery so as to capture the course of antepartum and inpatient care. In addition, hospital admissions up to one year after delivery are matched to the birth record. Death certificate data provide a measure of mortality, while the birth certificate includes a wealth of information about the parents and the circumstances of the birth itself.

The hospital discharge data include the patient's age, procedure and diagnosis codes, primary payer, day of the week, hospital ownership information, and admission and discharge date. Beginning in 1995, whether the birth was scheduled or unscheduled is reported as well.

Length of stay is reported in the data as the discharge date minus the admission date: the total number of midnights in care. The admission date is the date of birth for the newborn. ${ }^{8}$ The main measure of resource usage in the analysis will be the number of additional midnights in care:

\footnotetext{
${ }^{8}$ Despite the potential incentive on behalf of the patient or the insurer to record the admission date as after midnight, this does not appear to occur.
} 
the number of midnights in the hospital not counting the initial one that defines the threshold. That is, our measure for those born after midnight is the usual one; for those born before midnight, we subtract one from the usual length of stay so as to remove the mechanical midnight that is not related to the true length of stay in the hospital. ${ }^{9}$

The linked birth certificate data report pregnancy and birth characteristics that are not available in hospital discharge data. The pregnancy is described by the number of prenatal visits, as well as the presence of any complications, such as hypertension or diabetes. The use of ultrasound and amniocentesis is also recorded. Parents are described by their age and educational attainment, as well as the mother's birthplace. For the newborn, birth weight and gestational age (in days) are reported. When gestational age is used as a control, it is measured as the number of days not including the midnight that defines the threshold. While Race/Ethnicity of the newborn will be considered, Hispanic births were no longer separately identified in our data after 1995. We observe birth complications, including measures of the use of interventions, whether the labor was stimulated, and whether the labor was induced. The mother's day of admission and the precise time of birth, essential to implementing our design, are recorded. Discharge time is not recorded, so our length of stay measure is in days. While we would prefer a more detailed measurement of stay length, in the spirit of "not biting the hand that feeds," we

\footnotetext{
${ }^{9}$ Total hospital charges are available in the data, but those born just before midnight are billed for a night in care almost immediately and have slightly higher accounting charges despite spending less time in the hospital.
} 
note that its absence is presumably what makes our discontinuity design possible. Finally, it is possible that infants born prior to midnight may stay later on the day of discharge compared to newborns who stay an additional night in the hospital due to the post-midnight birth. As such, the results below consider the effect of having an extra night in the hospital.

\subsection{Analysis Sample}

The main analysis will consider vaginal births within 20 minutes of midnight; births by cesarean section will be considered separately. Newborns with lengths of stay of more than 28 days $(5.2 \%)$ are excluded. These outliers are less likely to be affected by the accounting rules and may skew the mean differences before and after midnight. To focus on patients where the births are most likely to have random variation with regard to the timing of the birth, unscheduled births are considered after 1995, which excludes $15 \%$ of the remaining births. Scheduled births will be considered separately as well. $1 \%$ of births were excluded because delivery took place outside of a hospital. Another $4 \%$ of the data have missing covariate information; results will be shown with and without these births. ${ }^{10}$

Figures of raw means by minute of birth and local linear regressions will be shown using data for every minute of the day. Models are also estimated with two samples: a 40-minute sample and a 2-hour sample,

\footnotetext{
${ }^{10}$ In the pooled sample over all of the years, post-midnight births are less likely to result from a c-section (17.5\% vs.18.8\%) and less likely to have stays of 28 or more days (4.6\% vs. $6.1 \%)$. Differences in home births, scheduled births, and missing covariates are small and not statististically significant across the groups.
} 
which include data within those windows around midnight. Due to the potential of measurement error (e.g. a spike in births on the hour typically identify births that occurred at any time during that hour or attempts to influence the reported length of stay of those born close to midnight by recording a time of before or after midnight) the main analysis excludes the births from 11:56 p.m. to 12:04 a.m. The 40-minute sample, then, includes births fewer than 20 minutes from 11:55 p.m. or 12:05 a.m. ${ }^{11}$

The final cut of the data considers infants born before and after the law change in California. The law came into effect on August 26, 1997. Births from January 1, 1991 to July 31, 1997 will be used to estimate the models before the law change, and births from September 1, 1997 to December 31, 2002 will be considered for post-law-change births. The resulting 40-minute samples include nearly 60,000 observations prior to the law change and over 30,000 observations after the law change.

\section{Model and Estimation}

We compare birth outcomes on either side of the midnight threshold. The effect of an extra night in the hospital on these outcomes we estimate is the ratio of the outcome difference and the length of stay difference. This estimate measures the local average treatment effect (LATE) for those

\footnotetext{
${ }^{11}$ The sample mimics the nonparametric estimates that include births less than 20 minutes from the threshold. With the threshold at minute $t=0$, this includes births from $-19 \leq t \leq 19$. These times are 11:37 p.m. to 11:55 p.m. and 12:05 a.m. to 12:24 a.m.
} 
infants who receive an extra night in the hospital as a result of being born after midnight [4]. Specifically, we are estimating effects for those who stay an extra night at the hospital because the infant is entitled to an extra day without charge due to the time of birth around midnight. Presumably, those induced to stay longer are not a random draw from the population. In particular, infants born around midnight likely differ from those planned to be born earlier in the day. For this reason, a priori our estimates may be expected to differ from those previously estimated using the minimum stay-length mandates. Further, infants induced to stay an extra night as a result of the time of birth around midnight exclude families who wish to leave the hospital soon after birth or newborns with serious health complications who will stay in the hospital much longer than two nights regardless (these groups are also excluded from the time-series estimates that consider the law changes.)

Our exposition of the potential outcomes framework (Section 4.1), conditions for LATE estimation (Section 4.2), and multi-valued treatment (Section 4.3) follows Angrist \& Imbens [3] and their example of estimating returns to schooling using the quarter of birth instrument closely.

\subsection{Potential Outcomes Framework}

First, we define the binary variable $Z$ :

$$
Z=\left\{\begin{array}{cc}
0 & \text { born just before midnight } \\
1 & \text { born just after midnight }
\end{array}\right.
$$

We are interested in the (multi-valued) treatment variable $L$, reflecting 
the length of hospital stay. For infants born close to midnight, we consider the number of additional midnights in care. Specifically, we define $L$ as:

$$
L=\left\{\begin{array}{cc}
0 & \text { no additional midnights } \\
1 & \text { one additional midnight } \\
2 & \text { two additional midnights } \\
J & \text { three or more additional midnights }
\end{array}\right.
$$

$L_{Z}$ is the number of additional midnights conditional on whether the infant was born just prior to midnight $(Z=0)$ or just after midnight $(Z=$ 1). Newborns are observed being born either before or after midnight, however, and what we actually observe is:

$$
L=L_{Z}=Z \cdot L_{1}+(1-Z) \cdot L_{0} .
$$

Further, we assume a set of potential health outcomes $Y_{j}$ (e.g. whether a newborn is re-admitted to a hospital in first 28 days of life) exists for each newborn for each of the possible durations of initial hospital stay $j$ $=0$ to $J$.

\subsection{Conditions required for estimating $L A T E$}

Three conditions must be met in order to interpret our estimate as a local average treatment effect. Again, this section follows Angrist \& Imbens [3].

\section{There is a first stage.}

$$
\operatorname{Pr}\left(L_{1} \geq j>L_{0}\right)>0 \text { for some } j .
$$


The probability of an additional midnight is higher for those born just after midnight for some length of stay $j$. We explore this condition empirically.

\section{Monotonicity}

$$
L_{1}-L_{0} \geq 0
$$

for each newborn with probability $1 .^{12}$ Anyone in the population who would stay an additional midnight were she born before midnight (a stay that would require physician approval for reimbursement) would also stay that additional midnight if she were born after midnight (when it is automatically reimbursed). This assumption is not verifiable because we only observe $L_{0}$ or $L_{1}$. Monotonicity would seem quite plausible in our application as those who were born before midnight and stayed an additional midnight in any event would receive a "free" night by being born after midnight. This condition serves to prohibit "defiers" (i.e. newborns who violate the monotonicity assumption by receiving extra time in the hospital due to being born earlier). ${ }^{13}$ Angrist \& Imbens [3] demonstrate that monotonicity has the testable implication that the c.d.f. of $L$ for those born just before and just after midnight should not cross. That our

\footnotetext{
${ }^{12}$ Alternatively, $L_{1}-L_{0} \leq 0$ for each newborn would also satisfy monotonicity, but is not plausible in this context.

${ }^{13}$ There could be a mechanical effect of a pre-midnight birth having a longer length of stay for a fixed discharge time, where an 11:30 p.m. birth would have an extra hour in care compared to one born at 12:30 a.m. This is one reason considering births just before and after midnight is important.
} 
data satisfy this implication is demonstrated in the results below.

\section{Independence}

$$
\left(L_{0}, L_{1}, Y_{0}, Y_{1}, Y_{2}, Y_{J}\right) \text { are jointly independent of } Z \text {. }
$$

The independence assumption is satisfied if the time of birth around midnight exhibits random variation. While not testable, we will consider the frequency of birth before and after midnight, as well as observable characteristics to consider whether those born after midnight appear different from those born before midnight.

\subsection{Multi-Valued Treatment}

Under the conditions above, the local average treatment effect is the ratio of the outcome difference to the length of stay difference. As $j$ ranges from 0 to $J$, the effect for increases in the number of nights from one to two; from two to three; and so on are averaged together to yield the "average causal response" [3]. ${ }^{14}$ The weight attached to each increment in stay length is given by:

\footnotetext{
${ }^{14}$ If a post-midnight birth induced an infant to stay two extra nights, then effects from such increases would be included in the weighted average as well. This might be possible if an extra night in the hospital leads to the detection of a problem that results in even longer lengths of stay. For the most part, however, the inducement is created by the entitlement to one more night and we consider the one-unit increases in lenght of stay as a result.
} 


$$
\varpi_{j}=\frac{\operatorname{Pr}\left(L_{1} \geq j>L_{0}\right)}{\sum_{i}^{J} \operatorname{Pr}\left(L_{1} \geq i>L_{0}\right)}
$$

which is proportional to:

$$
\operatorname{Pr}(L \geq j \mid Z=1)-\operatorname{Pr}(L \geq j \mid Z=0) .
$$

Passage of California Newborns' and Mothers' Act in 1997 changed the weights used to calculate the average causal response dramatically. Prior to the law change, the midnight threshold increased the number of additional midnights primarily from zero to one (or one to two total "nights" in the hospital). After the law change, stay length increased from one to two additional midnights due to the midnight rule (see Section 5.1.2 for details). By estimating results separately for births before and after the law change, the potential for diminishing returns to length of stay can be examined.

\subsection{Description of Compliers}

The local average treatment effect is the average treatment effect for " compliers": those who are induced to have a longer stay as a result of the post-midnight birth. In contrast, "always takers" or "never takers" have stay lengths that are unaffected by the minute of birth. It is not possible to identify the compliers, but it is possible to describe their average observable characteristics, $E\left(X \mid D_{1}=1, D_{0}=0\right) .{ }^{15}$

\footnotetext{
${ }^{15}$ Abadie [2] showed that characterisitics of compliers can be described using his kappa weighting scheme. It is also known that for binary characteristics and a binary
} 
For example, define the binary variable $D$ : to be an indicator for a long stay (e.g. more than 1 night prior to the law change and more than 2 nights after the law change):

$$
D=\left\{\begin{array}{cc}
0 & \text { short stay } \\
1 & \text { long stay }
\end{array}\right.
$$

Also define $D_{Z}$ as the value $D$ would take if $Z$ were either 0 or 1 . $Z$ is again assumed to be independent of $D$. Compliers in this context are such that $D_{1}=1$ and $D_{0}=0$.

For example, $E\left(X \mid D_{1}=1\right)=E(X \mid D=1, Z=1)$ represents the characteristics of those with long stays who are born after midnight and can be estimated by sample means. This can be written as a weighted average of the characteristics of always takers and compliers:

$$
\begin{aligned}
E\left(X \mid D_{1}=\right. & 1) \\
& =E\left(X \mid D_{1}=1, D_{0}=1\right) P\left(D_{0}=1 \mid D_{1}=1\right) \\
& +E\left(X \mid D_{1}=1, D_{0}=0\right) P\left(D_{0}=0 \mid D_{1}=1\right) .
\end{aligned}
$$

Always takers can be described by the characteristics of individuals who are born before midnight $(Z=0)$ yet have longer stays $(D=1)$. That is, the $E\left(X \mid D_{1}=1, D_{0}=1\right)=E\left(X \mid D_{0}=1\right)$, by the monotonicity condition $\left(D_{1}-D_{0} \geq 0\right)$. The last term is $E(X \mid D=1, Z=0)$, which can also be estimated by sample means.

For the probability terms:

instrument, the relative likelihood that an individual in a particular group is a complier is the ratio of the first-stage coefficient on the instrument estimated on that group's subsample to the first-stage coefficient for the full sample. 


$$
\begin{aligned}
& P\left(D_{0}=1\right) \\
& \begin{aligned}
=P\left(D_{0}=1 \mid D_{1}\right. & =1) P\left(D_{1}=1\right)+P\left(D_{0}=1 \mid D_{1}=0\right) P\left(D_{1}=0\right) \\
& =P\left(D_{0}=1 \mid D_{1}=1\right) P\left(D_{1}=1\right)
\end{aligned}
\end{aligned}
$$

by the monotonicity condition.

$P\left(D_{0}=1\right)$ and $P\left(D_{1}=1\right)$ can be estimated as the sample proportion of those born before midnight with long stays and the proportion of those born after midnight with long stays, respectively. The first is an estimate of the population proportion of always takers $\pi_{A}$, by the independence of $Z$. Similarly, for those born after midnight, those with short stays can be used to estimate the population fraction who are never takers, $\pi_{N}$. The proportion of the population who are compliers is then $\pi_{C}=1-\pi_{A}-\pi_{N}$, as "defiers" are assumed away by the monotonicity condition. Among the group born after midnight, the fraction with longer stays, $P\left(D_{1}=1\right)$, is $\pi_{C}+\pi_{A}$. Meanwhile, $P\left(D_{0}=1 \mid D_{1}=1\right)=\pi_{A} /\left(\pi_{A}+\pi_{C}\right)$, and $P\left(D_{0}=\right.$ $\left.0 \mid D_{1}=1\right)=\pi_{C} /\left(\pi_{A}+\pi_{C}\right)$.

(1) can then be re-arranged, and the expected characteristics of the compliers can be written as:

$$
\begin{aligned}
E & \left.E \mid D_{1}=1, D_{0}=0\right) \\
& =\frac{\pi_{C}+\pi_{A}}{\pi_{C}}\left[E\left(X \mid D_{1}=1\right)-\frac{\pi_{A}}{\pi_{C}+\pi_{A}} E\left(X \mid D_{1}=1, D_{0}=1\right)\right] \\
= & \frac{\pi_{C}+\pi_{A}}{\pi_{C}}\left[E(X \mid D=1, Z=1)-\frac{\pi_{A}}{\pi_{C}+\pi_{A}} E(X \mid D=1, Z=0)\right] .
\end{aligned}
$$

Each of the terms in (2) can be estimated in the sample. 


\subsection{Estimation}

We begin by examining the first stage - the relationship between the time of birth and the length of stay - and then proceed to the reduced form the relationship between the time of birth and the health outcomes. Local linear regressions before and after are estimated using a triangle kernel [17][7]. Asymptotic standard errors are also reported [22].

In addition, we estimate parametric models that include covariates and linear trends that vary before and after midnight. This is a simple local linear estimator with a rectangle kernel and where the weights do not decay as the distance from midnight increases [14]. For outcomes $Y$ (including length of stay, readmissions, and mortality), the models for infant $\mathrm{i}$ born at minute $t$ from a midnight $(t=0)$ cutoff are as follows:

$$
Y_{i t}=\beta_{0}+\beta_{1} 1(t \geq 0)+\beta_{2} 1(t \geq 0) * t+\beta_{3} 1(t<0) * t+\beta_{4} X_{i}+\varepsilon_{i t},
$$

where $\mathrm{X}$ is a vector of observable birth characteristics. ${ }^{16}$

This basic regression discontinuity model is estimated using Ordinary Least Squares for length of stay. Additional tests of robustness with regard to the estimation are also reported. For the binary outcomes of readmissions and mortality, probit models are estimated and marginal effects at the mean of the control variables are reported. Heteroskedasticity-robust standard errors are reported for these models.

\footnotetext{
${ }^{16}$ In practice, the analysis samples exclude births within 10 minutes of midnight. $t=-1$ just prior to the cutoff (11:55 p.m.) and $t=0$ at the cutoff (12:05 a.m.).
} 


\subsubsection{Choice of Bandwidth}

Across the outcomes, bandwidths of close to 10 minutes were found to minimize the sum of squared errors between the local linear estimator and a fourth-degree polynomial model estimated within two hours of midnight. Local estimation at a boundary is generally thought to require a somewhat larger bandwidth compared to interior points, and we applied a rule of thumb used in density estimation at a boundary of two times the crossvalidation bandwidth [26], or a twenty-minute pilot bandwidth in this case. Shorter and longer bandwidths are considered as well. Relatively wider bandwidths appear appropriate given that we find a sustained increase in length of stay following midnight, and if this length of stay affects

outcomes, a shift in the readmission or mortality rate should be sustained through the first hour as well. The tradeoff is that infants born far from midnight are more likely to differ from one another. We do not expect infants born at 11:00 p.m. to be so very different from those born at 1:00 a.m.

\section{Results}

\subsection{Unconditional Estimates}

\subsubsection{Frequency of Births Around Midnight}

Do physicians systematically misreport time of birth around the midnight threshold? As noted above, physicians may have an incentive to record 
births as occurring earlier or later than midnight. Figure 4 provides a visual check on this behavior, plotting the number of births by minute of the day [17]. Births are more frequent during "business hours" of 7:00 a.m. to 5:00 p.m. The frequency declines until midnight and remains fairly stable until around 7:00 a.m. The time of birth is more likely to be reported on the even hour and additionally at times ending in 0 or 5 , due to rounding.

Much of the analysis will focus on births between 11 p.m. and 1 a.m. and Figure 4B shows roughly 2500 births are recorded each minute, while 3000 births are found at the 5 minute marks. The largest spikes occur at 11:00 p.m. and 12:01 a.m. 12:00 midnight-the only time that uses the number 24 as the hour-has fewer observations $(\mathrm{N}=734)$, possibly due to physicians making clear that the birth occurred the following day. The spike at 12:01 is similar to the spike at 11:00 p.m., though it is slightly larger than the spike at 1:00 a.m. These spikes likely reflect births that occurred at any time during that hour-one reason to exclude births at 12:01 a.m. as most of these births occurred later in the hour. Other than births reported to occur at 2400 (midnight), the number of observations is similar in the hour before and after midnight. 153,180 births are recorded from 11:00 p.m. to 11:59 p.m. and 147,113 are reported from 12:00-12:59, or $4 \%$ more prior to midnight. This is similar to the $3 \%$ difference between the 10:00 p.m. hour and the 11:00 p.m. hour, though smaller than the midnight versus 1:00 a.m. comparison of less than 0.5 percent. ${ }^{17}$

\footnotetext{
${ }^{17}$ The fraction born after midnight tends to be close to 0.5 across hospitals and
} 


\subsubsection{Length of Stay}

Length of stay is measured as the number of midnights in care. If the minute of birth were unrelated to the timing of discharge, newborns with a time of birth just prior to midnight should have a length of stay recorded as one midnight longer than newborns born just after midnight, by definition.

Figure 5 reports the average length of stay by minute of birth, along with local-linear regression estimates. Panel A describes the relationship prior to the 1997 law change, and Panel B considers births after the law came into effect. Prior to the law change, the average length of stay is close to 1.5 days for births at noon, increasing to 2 days by midnight. After the law change, a similar picture is seen, although the average length of stay is shifted upwards by roughly 0.35 days in care. As expected, the number of midnights in care is higher for those born just before midnight, although the difference is significantly less than one. (Were just the mechanical effect at play, this difference should be close to unity.)

To consider the number of nights in the hospital, consider the number of additional midnights in care. Figures 6 and 7 also show the means of these additional midnight measures by minute of birth, as well as locallinear regression estimates. Before the law change, the local-linear regres-

dates. One date of interest is December 31, when a pre-midnight birth is subject to a tax deduction [10]. We find that births tend to be pushed toward January 1, reflecting possible benefits of being a "baby new year." In the two-hours around midnight, the highest proportion found to be born "after midnight" was on January 1, 2000 (72\%), followed by January 1, 2001 (67\%). January 1 1995, 1997, and 1998 are also in the top 100 dates in terms of the highest fraction of post-midnight births. 
sions show that $57 \%$ of those born just before midnight stay at least one more night in the hospital compared to $72 \%$ of those born after midnight. After the law change, $83 \%$ of those born just before midnight stay at least one extra night. After midnight the proportion has a smaller jump to 90\%. By comparison, the proportion of newborns staying at least two more nights increases from $11 \%$ to $17 \%$ before the law change and doubles from $16 \%$ to $32 \%$ after the law change. Once the newborn has stayed two nights, the post-midnight birth has a smaller effect.

To summarize Figures 5-7 and consider one of the estimation samples, Table 1 reports means for the 40-minute sample used in the estimation below. The increase in length of stay after the law change is evident: the average length of stay increases from 1.99 to 2.29 for those born before midnight, and from 1.23 to 1.58 for those born after midnight.

Additional midnights are simply the raw length of stay minus one for the births before midnight and equal to the raw length of stay for births after midnight. ${ }^{18}$ When births before and after midnight are compared, the average number of additional midnights increases from 0.99 to 1.23 before the law change and from 1.29 to 1.58 after the law change. This change is remarkably similar to the change in average length of stay following the law change, i.e. leaving aside the midnight discontinuity. This suggests that our use of the midnight accounting rule mimics the law's mandate that entitled newborns to 48-hour minimum stays when insur-

\footnotetext{
${ }^{18}$ When the length of stay for those born in the 11:00 hour was recorded as zero $(0.6 \%)$, this likely reflects measurement error and the number of additional midnights was set to zero.
} 
ance providers routinely reimbursed only 24-hours in care.

The next three rows of Table 1 report the proportion of newborns who stay at least one additional midnight, at least two, and at least three additional midnights. For each category, these measures are larger for those born after midnight, which is consistent with the monotonicity condition. As in Figures 5-7, before the law change, the increase in the number of additional midnights is most pronounced between 0 and 1 , whereas the jump after the law change is seen primarily for newborns staying 2 additional midnights as opposed to 1 . In terms of the local average treatment effect weights described in Section 4, prior to the law change, the weight on treatment increases from zero to one additional night is $73 \%$, while after the law change the weight on increases from one to two additional nights is $65 \% .^{19}$

\subsubsection{Health Outcomes}

In terms of health outcomes, we consider readmissions to the hospital and mortality rates. In particular, 7-day readmissions, 28-day readmissions, and total charges for any admission within 28 days or 1 year, as well as 28-

\footnotetext{
${ }^{19}$ Table 1 shows that the change in the proportion of infants born close to midnight who stay at least three additional midnights is smaller (on the order of 1-2 percentage points). Excluding these differences in stays of greater than 2 nights, the weights are proportional to the differences in proportions of children staying at least 1 vs. at least 2 additional midnights. Prior to the law change, the weight on stays increasing from zero to one additional night is $(73-57) /((73-57)+(17-11))=73 \%$. After the law change, the weight on stays increasing from one to two nights is $(32-15) /((32-15)+(91-82))=65 \%$.
} 
day and 1-year mortality are considered. The 7- and 28-day measures are calculated from the midnight in question. For example, 28-day readmission is coded to 1 if the difference between the readmission date and the date of birth were less than or equal to 28 for those born after midnight, and less than or equal to 29 for those born just prior to midnight.

Table 1 shows that health outcomes are similar for those born before or after midnight, with statistically and economically insignificant differences. The readmission rates and associated hospital charges are slightly larger for those born after midnight (the group with longer spells in the hospital), although the result is statistically significant only for the 28-day readmission rate in the time period before the law change.

Mortality is less frequently observed, with 28-day mortality rates for this analysis sample of 3 per 1000 and 1-year mortality rates of 4-5 per 1000. Lower mortality rates after the law change are largely due to the exclusion of scheduled, and potentially riskier, births (these births are excluded beginning in 1995 due to data availability). The mortality rates are similar before and after midnight, with differences that are not statistically significant. These results are perhaps better interpreted in the context of variation in mortality rates across the day.

Figures 8 and 9 report the local-linear regression results for readmission rates and mortality rates. Figure 8 considers births before the law change, whereas Figure 9 reports the results after the law change. The estimates are based on the 24-hour sample to allow an examination of typical variation in these outcomes over the course of the day, and a bandwidth of 20 
minutes is used for the local-linear regression estimates. Little change is found before and after midnight for these outcomes.

For a magnified view, Appendix Figures A2 and A3 report the results from 8 p.m. to 4 a.m., and for further comparison a bandwidth of 10 minutes was used. Figure A2B shows a slight increase in 28-day readmissions following the midnight birth, and Figure A2C shows that the 1-year mortality rate is close to 6 per 1000 in the minutes from 11 p.m. to 1 a.m., with noisier measurements at the boundary. After the law change, any differences in mortality rates shown in Table 1 for the 40-minute sample are not found to be sustained in the minutes after 12:20 a.m.

\subsection{Including Covariates}

One reason why the outcomes may not differ is that the beneficial effects of an additional night in the hospital may be masked by a population born after midnight that is in worse health. Table 2 reports means of selected covariates for the 40 minute sample. This is for the pooled sample of births from 1991-2002. Means are reported for each sub-period in the appendix.

Mean differences are small across the covariates. For example, the average age of 26.8 is identical across the two groups. Some small differences are found. $20.4 \%$ of women with births after midnight had fewer than 9 prenatal visits compared to $19.9 \%$ for births after midnight, whereas the means for 9-15 prenatal visits are $68.9 \%$ and $69.5 \%$, respectively. Educational characteristics, are nearly identical, including missing data for fathers which can be seen as an indicator of single-parent births. An 
indicator for the mother's first birth is slightly smaller for births after midnight (39.4\% vs. 40\%), largely due to a difference in the post-1997 period. Those born after midnight are slightly less likely to be white $(53.7 \%$ vs. $54.4 \%$, although the differences are not statistically significant in the two sub-periods. The use of forceps or vacuum to speed the delivery is slightly less likely after midnight (9.5\% vs. 9.9\%), although other measures of labor being stimulated or induced are not different, especially in the pre-1997 time period. Births prior to midnight are slightly higher in for-profit hospitals (14.2\% vs. $13.6 \%$ ). Out of the 56 characteristics listed in Table A1, 6 have statistically significant differences in the pre-law period, and 5 have statistically significant differences in the post-law period. Most of these differences do not appear economically significant (often indistinguishable out to 2 significant digits), despite the statistical significance due to the large sample size. When the post-midnight indicator is regressed on the observable characteristics, the F-test fails to reject that all of the coefficients are zero (F-stats of 1.13 and 1.05 for the two time periods ; p-values of 0.17 and 0.35$)^{20}$ It appears that births just after midnight are similar to those just before midnight.

\subsubsection{Length of Stay}

Table 2 suggests that controlling for observable characteristics should have little effect on the results, and this is confirmed in Tables 3-5. Table

\footnotetext{
${ }^{20}$ These tests exclude $1 \%$ of the observations with "missing admission day of the week for the mother": a variable that is associate with a post-midnight birth. Results are identical when these cases were excluded from the main analysis.
} 
3 reports the results for the first-stage relationship between additional midnights in care and an indicator that the birth occurred after midnight. Column 1 reports the difference in the local linear regression estimates separately estimated before and after midnight. A bandwidth of 20 is used, which includes data in the 40 minute sample as described above. The estimate before and after the law change is similar: 0.27 vs. 0.26 , although the estimates are differences from a different base: 1.00 before the law change and 1.30 afterwards. The estimates are highly significant, with standard errors of close to 0.04 .

Columns (2)-(5) are estimated by OLS with controls for linear trends in minutes from the midnight cutoff, trends that are allowed to vary before and after midnight, as described above. Note that minutes from the cutoff is positive after midnight and negative before midnight. Using the same 40-minute window as the local linear results, but with a sample that includes nonmissing covariates, the results are similar: 0.29 before and 0.24 after the law change. A full set of birth characteristics listed in Table A1, as well as individual indicators for mother's age, father's age, year of birth, and month of birth are included in models reported in Column (3). ${ }^{21}$ Coefficients are similar, however $(0.27$ and 0.23$)$. The robust standard errors are similar to the asymptotic standard errors calculated in Column (1), though they are slightly smaller.

The two-hour window includes 162,821 observations before the law

\footnotetext{
${ }^{21} \mathrm{An}$ indicator for mother's age being less than 16, each age, and then greater than 40, as well as a missing age indicator is included. Similar indicators for father's age are included as well.
} 
change and 94,879 after the law change. The estimates based upon this sample are 0.22 and 0.25 before and after the law change, respectively, regardless of the use of controls. The use of the two-hour window provides more precise estimates, at a cost of possible misspecification bias with the inclusion of births farther from the discontinuity and linear trends that may not adequately control for the variation in the data. Overall, postpartum length of stay is $0.22-0.27$ days longer for those born after midnight, or close to $20 \%$ of the pre-midnight means.

Similar estimates are found when length of stay is treated as a count variable and a negative binomial model is estimated with full controls, with the marginal effect of a post-midnight birth estimated to be 0.203 $($ s.e. $=0.015)$ before the law change and $0.244($ s.e. $=0.020)$ after the law change. Further, the length of stay may be considered censored when a newborn is discharged to another facility or when a newborn dies in the hospital (1.5\% of the sample). When a Cox proportional hazard model of the additional midnights in care +0.5 was estimated with full controls and taking into account this possible censoring, the estimated change is slightly smaller with the hazard ratio estimated to be $0.858($ s.e. $=0.005)$ before the law change and 0.831 (s.e. $=0.007$ ) afterwards. Similar firststage and reduced-form results are found when the censored observations were excluded from the analysis as well.

To place the estimate of 0.25 in context, Appendix Table A2 includes the covariates for a pooled sample from 1991-2002. Similar differences in length of stay are found for 1st births (0.23), 30-year old mothers compared 
to 20-year olds (0.28), missing father's information (0.20), and labors that were over 20 hours (0.26). Low birthweight babies had larger relationship with length of stay (coefficient $=0.7$ ) and government hospitals had longer stays than for-profit hospitals (coefficient $=0.44$ ).

\subsubsection{Newborn Outcomes}

Table 4 considers readmissions at the 7 - and 28- day levels. Columns (1) and (5) report the local-linear regression estimates using the 20 minute bandwidth. Virtually no difference is found in 7-day readmissions in both time periods for those born before or after midnight, with an estimated increase in readmissions of $0.04 \%$ or $1.4 \%$ of the pre-midnight mean, despite longer stays in care. Higher 28-day readmission rates are found for those born after midnight prior to the law change (an increase by 0.5 percentage points, compared to a mean of $4 \%$ ), although the difference is not statistically significant with a standard error of 0.4 percentage points. After the 1997 law change, 28-day readmissions are found to be 0.4 percentage points lower for those born after midnight, although the result is again not statistically significant.

Columns (2) and (3) consider the same 40-minute sample using the probit model described above. The outcome differences are again small for the 7-day readmissions and change sign to negative after the 1997 law change. Before the law change, 28-day readmissions show slightly larger increases for those born after midnight. After the law change the results are similar to the local-linear estimation, and when the two-hour sample 
is considered, the coefficient is smaller in magnitude (-0.0008).

The small magnitudes and the instability of the signs, which are contrary to a diminishing returns possibility given the positive point estimates in the pre-law period and negative coefficients in the post-law period, are consistent with Figures 8 and 9 that outcomes look similar before and after midnight.

In terms of precision, the two-hour sample provides somewhat smaller standard errors, and as long as births early in the 11 p.m. hour are similar to births in the late 12:00 a.m. hour, they should yield meaningful results. For these samples even the lower limit of the $95 \%$ confidence interval suggest small decreases in the likelihood of readmission for infants born before and after midnight-generally less than $10 \%$ of the pre-midnight mean. ${ }^{22}$.

Table 5 considers the mortality results. The 28 -day mortality rate in this sample is 3.5 per 1000 prior to the law change and 3.0 per 1000 after

\footnotetext{
${ }^{22}$ In terms of 7-day readmissions, the lower limit of the $95 \%$ confidence interval prior to the law change is -0.0016 and after the law change it is -0.0025 , or between 6 and 9\% lower than the pre-midnight mean. When a "four-hour" sample is considered, the point estimate is 0.002 , with a lower limit of the $95 \%$ confidence interval greater than zero (0.0001). Similarly, the estimates of the 28-day readmission differences have $95 \%$ confidence interval limits as low as -0.0010 and -0.0063 before and after the law change, respectively. These estimates represent decreases in readmissions of $2 \%$ before the law change and $13 \%$ after the law change. Again, when a "four hour sample" is considered, the point estimate prior the law change is 0.002 , with a lower limit on the $95 \%$ confidence interval of -0.0002 (or $0.5 \%$ of the mean); after the law change the estimates are -0.0007 and -0.004 (or $8.5 \%$ of the mean).
} 
the law change. The coefficients on being born after midnight are close to zero in both time periods and are of unstable sign. In both the 40-minute and 2-hour samples, the lower limit on the 95-percent confidence interval is -0.0002 , or $5 \%$ of the pre-midnight mean. After the law change, the lower limits are -0.00007 and -0.00016 (or $2-5 \%$ of the mean).

In terms of 1-year mortality, some of the coefficients found are fairly large, but they are not robust. For example, the local-linear estimation prior to the law change, and the probit models using the 2-hour samples before and after the law change, yield coefficients that are essentially zero. The results are less precisely estimated, however, and using the 2-hour samples, the lower limit on the $95 \%$ confidence intervals is -0.0007 and 0.0006 for the two time periods (or $13 \%$ of the pre-midnight means). While fairly large effects are within the confidence interval for 1-year mortality, the lack of robustness of any beneficial effect of longer stays associated with an after-midnight birth again confirms the intuition from Figures 8 and 9 that outcomes look remarkably similar despite the difference in length of stay for the two groups.

To place these results in context, Table A2 includes the estimated marginal effects of the covariates evaluated at the sample mean. In terms of statistical significance, patients with few prenatal visits, boys, newborns with a low birthweight, and Medicaid patients tend to have worse outcomes. Newborns to new mothers were more likely to have a readmission (14\% higher than the mean), but little difference is found in terms of mortality. Other covariates, such as maternal education, are found to have 
little relation to infant mortality (controlling for the other covariates).

\subsubsection{Results Across Subgroups}

The data were explored to test the robustness of the main results and to consider subgroups that have been identified in previous research to benefit from longer stays. Table A3 reports the results for 12 subgroups of patients including scheduled births, c-section births, those with a birthweight of less than 3000grams, mothers who are high-school dropouts, Medicaid patients, births in for-profit hospitals and Kaiser hospitals, births following a pregnancy or labor complication, and a comparison of births whose observable characteristics suggested they were at high (or low) risk of 28day readmission. ${ }^{23}$ Results when no restrictions were placed on the sample are reported as well.

The first column shows that the first stage is generally robust across the groups. Table 3 showed that for the two-hour sample, the coefficient on a post-midnight birth is 0.22 prior to the law and 0.25 after the law. The ratio of the first-stage coefficients for each subgroup compared to the overall first-stage coefficient describe the relative likelihood that a particular group is a complier. Complier characteristics are discussed in depth below.

Before the law change, Medicaid patients have a larger jump at midnight. When a model was estimated that interacted Medicaid stauts with

\footnotetext{
${ }^{23} \mathrm{~A}$ probit for 28 -day readmission was estimated using the full set of control variables and the sample was divided into two groups based on the median predicted probability of readmission.
} 
the post-midnight indicator, as well as the linear trend terms, the nonMedicaid jump is estimated to be 0.175 and the jump for Medicaid recipients is found to be 0.25 , or $43 \%$ larger. Larger jumps in length of stay for post-midnight births before the law change are also found for unmarried mothers, a variable that is often missing and only available for 2 years after the law change. Births with complications tend to have smaller jumps at midnight.

After the law change, for-profit hospitals have a larger jump (coefficient of 0.31 , whereas newborns with a birthweight of less than 3000 grams have a smaller increase (0.09, compared to a mean of 2.05). Kaiser hospitalshospitals where the insurer owns the hospital and the billing rules may be expected to be less salient in terms of hospital incentives to extend the length of stay-tend to have shorter lengths of stay for everyone, by approximately 0.1 nights on average. They also have smaller jumps at midnight (0.19 before the law change and 0.09 after the law change). ${ }^{24}$ Last, when all data are considered, the jump is estimated to be 0.13 prior to the law change - smaller due to the inclusion of some births with very long lengths of stay - and 0.30 after the law change.

In terms of outcomes, out of the 26 probit models estimated, 2 were found to be statistically significant at an 5\% level (uncorrected for the number of tests considered), and both were in the pre-1997 time period. Patients with a labor complication and having a longer length of stay due

\footnotetext{
${ }^{24}$ In addition, the frequency of births before and after midnight do not appear to show strategic recording of the times.
} 
to a post-midnight birth are found to have higher 28-day readmission rates (coefficient of 0.005 or $13 \%$ of the pre-midnight mean). C-section patients, who are entitled to 4 days in care, also have longer lengths of stay when the procedure was conducted after midnight (coefficient of 0.23 compared to a mean number of additional midnights of 2.9.). These post-midnight births are found to have a lower 1-year mortality rate (coefficient of -0.002 or $22 \%$ of the pre-midnight mean). Given the large number of tests, these results should be regarded with caution, however.

In terms of patients who have a high-risk of readmission based on the observable characteristics (with readmission rates of close to $6 \%$ and mortality rates of 7-9 per thousand), higher readmissions and mortality rates are found for post-midnight births in the pre-1997 period, whereas lower readmission and mortality rates are found for those births in the post-1997 period. Indeed, of the 13 groups, 6 had negative coefficients on post-midnight birth when 1-year mortality was considered both before and after the law change. For 28-day readmissions 6 had negative coefficients after the law change, while 2 had negative coefficients before the law

change. Again, the instability of the signs and the (economically) small point estimates suggest that there is little relationship between longer lengths of stay and readmissions or mortality.

\subsubsection{Complier Characteristics}

In a local average treatment effect setting such as this, the estimated effects apply to a population of compliers: those who are induced to have 
a longer stay as a result of the post-midnight birth. Compliers are likely to differ from a random draw from the population. In particular, the results are most likely to apply to uncomplicated births where the minute of birth is plausibly exogenous and the stay length is not expected to be especially long so that the one- or two- day billing rules are more likely to bind.

While it is not possible to identify individual compliers in the data, it is possible to estimate their mean observable characteristics, as described in Section 4.4. Births of at least one additional midnight before the law change and at least 2 additional midnights after the law change were coded as receiving the longer-stay "treatment" $(D=1)$. The estimated fraction of compliers is similar in the two time periods (16\% prior to the law change and $17 \%$ after the law change). Always takers are more common prior to the law change, when the threshold for a longer stay is lower (57\% vs. $15 \%)$. Given these proportions and the average characteristics of always takers, $E(X \mid D=1, Z=0)$, along with the average characteristics of patients who are either always takers or compliers, $E(X \mid D=1, Z=1)$, we calculated the implied means of the complier characteristics, as shown in Appendix Table A4.

Overall, it appears that the compliers are quite similar to the population of births close to midnight. The main difference is that the compliers are less likely to be low birthweight and less likely to be full term, as expected. Across the two time periods, we also find that the complier group is slightly less likely to be the result of a stimulated labor, and the mother is more likely to have been admitted on a weekend. Before the law 
change, we generally find that those who are more likely to be disadvantaged are also more likely to be compliers (mothers who are high school drop outs, missing father's education, and Medicaid recipients). After the law change, the reverse tends to be found, with compliers more likely to be privately insured. There are exceptions in both time periods, however, and the differences tend to be small. Compared to the full population of births, the mean characteristics of the compliers are rarely statistically significantly different, although the estimated differences point to less complicated cases among the compliers. ${ }^{25}$ In both time periods the midnight births are less likely to be low birthweight, more likely to be Medicaid recipients, and the mother is more likely to be admitted on a weekend reflecting the fewer scheduled births around midnight. Prior to the law change, midnight births are to parents with slightly less education and less likely to be white After the law change, the differences tend to be smaller, however.

The compliers from the pre-post law change were also considered using all data from January-August in 1997, 1998, and 1999 (excluding stays of

\footnotetext{
${ }^{25} 95 \%$ confidence intervals were constructed using a bootstrap procedure, where the sample was re-drawn 300 times and the weights for compliers and always takers were re-estimated each time to reflect variation in these estimates. Prior to the law change, compliers are (statistically significantly) more likely to be Hispanic and have a mother admtted on a weekend. Meanwhile, parents' ages are younger, and the newborns are less likely to be low birthweight. After the law change, there are differences in prenatal visits (compliers are more likely to have fewer than 9), compliers are also less likely to be a first birth or an induced birth.
} 
more than 28 days). Evans et al. [11] noted that some Medicaid recipients were excluded from the law for the middle time period while all were covered from January 1999 onwards. To define compliers, the "treatment" is a stay of 2 or more days in the hospital or 4 days for c-section births $(\mathrm{D}=1)$, and the estimated proportion of compliers is 0.21 and 0.25 for the 1998 and 1999 time periods. Similar to our characteristics, this group is also less likely to be low birthweight (constituting approximately $2.5 \%$ of compliers vs. $6 \%$ overall). Other characteristics show larger differences: Compliers before the law change are much less likely to be births to mothers with less than a high school eduction (approximately $18 \%$ vs. $31 \%$ overall) and more likely to be college graduates (32\% vs. 19\%). As expected, the compliers are less likely to receive Medicaid in the middle time period (19\% vs. $42 \%$ ), but also in the period when all births are covered ( $27 \%$ vs. $42 \%)$.

\subsubsection{Maternal Outcomes}

Table 6 considers maternal length of stay and readmissions, although adverse outcomes are more rare among mothers. ${ }^{26}$ The mother's length of stay was calculated as the number of additional midnights after the birth of the child. The post-midnight increase is similar to that for newborns (0.30 and 0.23), although it is larger relative to the (smaller) mean length of stay for mothers (both time periods). Despite the longer length of stay

\footnotetext{
${ }^{26}$ The death certificate data were linked only for newborns. When in-hospital mortality was considered within 1 year for mothers, that mortality rate was 8 per 100,000 and the estimates before and after midnight were much noisier.
} 
for mothers who give birth after midnight, little relationship is found for readmissions. 28-day readmissions are rare ( 8 per thousand), and a birth after midnight is associated with a small decline in readmissions prior to the law change, and a small increase after the law change, although neither difference is statistically insignificant.

\subsubsection{Further Robustness Checks}

Other measures of readmissions were considered as well. Little difference in readmissions for jaundice or dehydration among newborns, or common diagnoses such as major puerperal infection for mothers, was found. One explanation for the slight increase in 7 - and 28-day readmissions could be due to discharges earlier in the day for those who receive an extra night in the hospital where a problem may be discovered soon after the child returns home and it is still "business hours." When 3-28 day readmissions are considered, the estimated effects are again close to zero. In addition, total hospital charges associated with readmissions within 28-days after the midnight in question or 1-year after birth were considered, again with little (and statistically insignificant) differences.

Other models included hospital fixed effects, hospital -by- date fixed effects, a difference-in-difference considering different sized jumps in length of stay at midnight across hospitals; a triple difference strategy considering these jumps before and after the law change; the zero result remains robust. 


\section{Interpretation}

Our results suggest that extending the length of stay by an additional night provides little health benefit for uncomplicated births. ${ }^{27}$ Minimum stay laws, in place for the last decade, have had large costs. Cost estimates for an extra night in the hospital are generally in the range of $\$ 1000$. With 4.6 million births per year, an increase of 0.25 days would be on the order of $\$ 1.1$ billion per year (or $\$ 11$ billion since 1997$).{ }^{28}$

The California dataset includes information on charges, and we consider all births with a birthweight over 2500 grams born at any time of day. Facility charges for the mother and infant were deflated by a Centers for Medicare and Medicaid cost-to-charge ratio. Costs were then regressed on length of stay, with full controls; this yields an estimate of approximately $\$ 2200$ (in 2008 dollars) per additional midnight. ${ }^{29}$ When the sample is

\footnotetext{
${ }^{27}$ Obviously, whether a birth is "uncomplicated" is known prior to when length of
} stay is generally determined.

${ }^{28}$ Madden et al. [15] finds an HMO's expenditure related to an extra night to be on the order of $\$ 1000$. Similarly, Raube \& Merrell [23] find that extra charges are on the order of $\$ 1000$ in the mid 1990s. A lower estimate would come from Russell et al. [24], who use the 2001 Nationwide Inpatient Survey and finds average (facility) costs of $\$ 600$ per delivery (for births $>2500 \mathrm{~g}$ ). Schmitt et al. [25] uses 2000 California data and finds the average cost for mothers and newborns is $\$ 4750$ ( $\$ 3100$ for mothers and $\$ 1650$ for infants), again for newborns $>2500 \mathrm{~g}$.

${ }^{29}$ Estimate from a regression of deflated charges on length of stay. The cost-tocharge ratio was substituted by the state median when it was in the extremes of the data, as suggested by CMS. When the charges were not deflated, an additional day is associated with approximately $\$ 3000$ in charges $(\$ 1300$ when stays of less than 3 days were considered, in 1996 dollars). Charges are generally greater than measures of costs, 
restricted to patients with fewer than 3 days in care, an extra night is associated with a cost of $\$ 1300$. These costs do not include physician fees, however. If we consider the budgetary cost of an extra night in a California hospital to be roughly $\$ 1500$, an increased length of stay of 0.25 days on average would cost roughly $\$ 400$ per birth or $\$ 200$ million per year.

The main welfare benefit would come from reductions in mortality attributable to longer hospital stays. ${ }^{30}$ The point estimates are generally small, unstable in sign, and any economically significant effects are not found to be robust (Figures $8 \& 9$ ). In fact, the point estimates tend to suggest worse outcomes associated with post-midnight births. Even at the lower limits of the $95 \%$ confidence interval for 28-day mortality (mortality potentially most likely to respond to an extra night in the hospital), the implied cost of saving a statistical life range from $\$ 2$ to $\$ 6$ million, which are greater than value-of-statistical-life estimates, such as $\$ 1.9$ million by Ashenfelter \& Greenstone [5]. ${ }^{31}$ Overall, it appears that longer lengths though they do not include physician fees which can constitute a similar percentage of resource use as the markup between charges and costs.

${ }^{30}$ Using our design, facility charges associated with readmissions are not found to be related to the time of birth. Even at the lower end of the $95 \%$ confidence interval, the readmission charges are $\$ 300$ lower for post-midnight births prior to the law change and only $\$ 40$ lower after the law change.

${ }^{31}$ The lower limits range from -0.0002 to -0.0007 . $\$ 400 / 0.00002=\$ 2 \mathrm{~m}$. When 1-year mortality is considered, the point estimates are again zero, although the confidence intervals widen to include cost of saving a statistical life on the order of $\$ 500,000$. Similarly, when an IV model was estimated, the point estimates are zero, although confidence intervals are wider and a $\$ 250,000$ cost of saving a statistical life cannot be rejected. 
of stay associated with minimum-stay mandates are not worth the extra expense for uncomplicated births, at least measured by readmission and mortality outcomes.

These costs of saving a statistical life are relevant in terms of comparing expenditures on this health initiative compared to others. Nevertheless, marginal social costs of an additional night in the hospital may be low given the availability of hospital staff regardless of the number of births on a particular day. We considered times when the hospital had an unusually large number of births around the midnight in question to consider the effects of a post-midnight birth when the marginal cost of a bed is likely higher. We found small decreases in length of stay for all of the newborns, but the jump at midnight was not affected. ${ }^{32}$

\footnotetext{
${ }^{32}$ For example, we found similar estimates when we controlled for the number of births in the 5 days before and after the midnight used to define the threshold. The average hospital records 5 births per day. We also considered the total number of births two days prior and one day after the midnight in question. Again, the first stage coefficient is unaffected by including this measure, which is slightly negatively related to the number of additional midnights (coefficient $=-0.007$, s.e. $=0.0007$ ). To consider times when the hospitals are particularly busy, we calculated the maximum number of 3-day birth counts and considered the number of births in the 3 days around the midnight in question as a fraction of this maximum capacity. Busier times are associated with slightly shorter lengths of stay in the time period before the law change, but the change in length of stay with regard to the minute of birth is not found to be affected.
} 


\subsubsection{Limitations}

Four main limitations should be considered when interpreting the results. The main question concerns external validity. The results presented here reflect the effects of longer stay lengths on outcomes for uncomplicated births where the time of birth is plausibly exogenous. Scheduled births generally occur in the morning and the effects of an additional night in care for these births are beyond the scope of this research design. However, uncomplicated births may be expected to be the ones where minimumstay laws are most likely to bind. Indeed, Evans et al. [11] found larger reductions in early-discharge among uncomplicated vaginal deliveries than either "complicated" vaginal deliveries or c-section deliveries following implementation of the laws in California. In addition, the similarity of the size of the effect of a post-midnight birth and the California law change on length of stay suggests that the extra night of reimbursable care afforded to post-midnight births mimics the effect of such a law change.

Second, the outcomes considered here, while particularly costly, do not consider other potential benefits to parents and infants. Longer stays may provide benefits in terms of additional rest and supervision.

Similarly, a third limitation is that outpatient care is not considered, and this care may substitute for postpartum hospital stays. For newborns who stay in the hospital for fewer than two days, California law mandates that insurance must cover a follow-up visit either at a physician's office or at home As with length of stay accounting rules, a birth just after midnight may be more likely eligible for such a home health visit. Previous evidence 
of nearly perfectly inelastic demand for these early follow-up visits, as described in the background section, suggests that the lack of an outcome difference is unlikely to be masked by a substitution toward greater use of outpatient care.

Fourth, as in the time-series results in the previous literature, comparisons of effects before and after the law change may incorporate differences in policies and practices that may have changed during this time period in addition to the change in baseline length of stay. As noted above, we do not find sudden changes in procedure use that can be attributed to the law change.

\section{Conclusions}

This paper makes use of a rule of thumb in patient billing which approximates the length of California hospital stays with the number of midnights in hospital following delivery. In apparent response to the discontinuous financial incentives, infants born just after midnight remain in the hospital about 0.25 additional nights compared to infants born just prior to midnight. These infants appear very similar in terms of observable characteristics. In addition, the 1997 early discharge law in California allows us to consider estimates that are drawn mainly from newborns induced to stay one additional midnight prior to the law change and a second mid-

night in the post-law period. In the presence of diminishing returns to stay length, we would expect to observe a larger health benefit of being born shortly after midnight prior to the law. 
We find no outcome differences associated with post-midnight birth, even among births prior to the minimum-stay law. Our impact estimates are fairly precise: at the endpoints of our confidence intervals, the most "optimistic" impact estimates would not justify the cost of the longer stays. This finding suggests that physicians can identify newborns who require additional time in the hospital and that the technology of postpartum care is such that it can be administered effectively on the first day of life. This finding is consistent with profit-maximizing HMOs in the early 1990s driving down stay lengths, despite having to reimburse hospitals for (relatively costly) readmissions.

These results apply to uncomplicated births where the exact minute of birth is plausibly exogenous; more complicated births that are planned for the morning hours are beyond the scope of this research design. Further, the outcomes considered here do not include benefits to parents from more rest and supervision in the hospital. For uncomplicated births - births where the early-discharge laws were most likely to bind - it appears that longer hospital stays yield little in terms of health gains, at least in terms of hospital readmissions and mortality rates. 


\section{References}

[1] A.A.P. 2004. Hospital Stay for Health Term Newborns. Pediatrics, 113(5), 1434-1436. American Academy of Pediatrics, Committee on Fetus and Newborn.

[2] Abadie, Alberto. 2003. Semiparametric Instrumental Variable Estimation of Treatment Response Models. Journal of Econometrics, 113, 231-263.

[3] Angrist, Joshua D., \& Imbens, Guido W. 1995. Two-Stage Least Squares Estimation of Average Causal Effects in Models with Variable Treatment Intensity. Journal of the American Statistical Association, 90(430), 431-442.

[4] Angrist, Joshua D., Imbens, Guido W., \& Rubin, Donald B. 1996. Identification of Causal Effects Using Instrumental Variables. Journal of the American Statistical Association, 91(434), 444-455.

[5] Ashenfelter, Orley, \& Greenstone, Michael. 2004. Using Mandated Speed Limits to Measure the Value of a Statistical Life. Journal of Political Economy, 112(1), S226-S267. part 2.

[6] Charles, Seymour, \& Prystowsky, Barry. 1995. Early discharge, in the end: maternal abuse, child neglect, and physician harassment. Pediatrics, 96(4), 746-747. part 1.

[7] Cheng, Ming-Yen, Fan, Jianqing, \& Marron, JS. 1997. On Automatic Boundary Corrections. Annals of Statistics, XXV, 1691-1708. 
[8] Coase, Ronald H. 1960. The Problem of Social Cost. Journal of Law and Economics, III(October), 1-44.

[9] Curtin, Sally C., \& Kozak, Lola Jean. 1998. Decline in U.S. Cesarean Delivery Rate Appears to Stall. Birth, 25(4), 259-262.

[10] Dickert-Conlin, Stacy, \& Chandra, Amitabh. 1999. Taxes and the Timing of Births. The Journal of Political Economy, 107(1), 161-177.

[11] Evans, William N., Garthwaite, Craig, \& Wei, Heng. 2008. The Impact of Early Discharge Laws On the Health of Newborns. Journal of Health Economics. forthcoming.

[12] Galbraith, Alison A., Egerter, Susan A., Marchi, Kristen S., Chavez, Gilberto, \& Braveman, Paula A. 2003. Newborn Early Discharge Revisited: Are California Newborns Receiving Recommended Postnatal Services. Pediatrics, 111(2), 364-371.

[13] Hyman, David A. 2001. What Lessons Should We Learn From DriveThrough Deliveries? Pediatrics, 107(2), 406-407.

[14] Imbens, Guido, \& Lemieux, Thomas. 2007. Regression Discontinuity Designs: A Guide to Practice. NBER Technical Working Paper No. 337, April.

[15] Madden, JM, Soumerai, SB, Lieu, TA, Mandl, KD, Zhang, F, \& RossDegnan, D. 2002. Effects of a law against early postpartum discharge on newborn follow-up, adverse events, and HMO expenditures. New Enlgand Journal of Medicine, 347(25), 2031-2038. 
[16] Malkin, Jesse D., Broder, Michael S., \& Keeler, Emmett. 2000. Do Longer Pospartum Stays Reduce Newborn Readmissions? Analysis Using Instrumental Variables. Health Services Research, 35(5), 1071-1091. Part II.

[17] McCrary, Justin. 2007. Manipulation of the Running Variable in the Regression Discontinuity Design: A Density Test. Journal of Econometrics. Forthcoming.

[18] Meara, Ellen, Kotagal, Uma R., Atherton, Harry D., \& Lieu, Tracy A. 2004. Impact of Early Newborn Discharge Legislation and Early Followup Visits on Infant Outcomes in a State Medicaid Population. Pediatrics, 113(6), 1619-1627.

[19] Medi-Cal. 2007. Contracted Inpatient Services for Medical Services. Sacramento: California DHHS.

[20] NCHS. 2000. National Hospital Discharge Summary: Annual Summary, 1998. Vital and Health Statistics, 13(148). National Center for Health Statistics.

[21] Paul, Ian M., Lehman, Erik B., Hollenbeak, Christopher S., \& Maisels, M. Jeffrey. 2006. Preventable Newborn Readmissions Since Passage of the Newborns and Mothers' Health Protection Act. Pediatrics, 118(6), 2006;118;2349-2358.

[22] Porter, Jack. 2003. Estimation in the Regression Discontinuity Model. Working Paper. 
[23] Raube, Kristiana, \& Merrell, Katie. 1999. Maternal Minimum-Stay Legislation: Cost and Policy Implications. American Journal of Public Health, 89, 922-923.

[24] Russell, Rebecca B., Green, Nancy S., Steiner, Claudia A., \& et al. 2007. Cost of Hospitalizations for Preterm and Low Birth Weight Infants in the United States. Pediatrics, 120, e1-e9.

[25] Schmitt, Susan K., Sneed, LaShika, \& Phibbs, Ciaran S. 2006. Costs of Newborn Care in California: A Population-Based Study. Pediatrics, 117, 154-160.

[26] Zhang, S., \& Karunamuni, R.J. 1998. On kernel density estimation near endpoints. Journal of Statistical Planning and Inference, 70, 301316. 
Table 1: Time of Birth, Length of Stay, and Infant Outcomes: 40 Minutes Around Midnight Sample

\begin{tabular}{|c|c|c|c|c|c|c|c|}
\hline & & \multicolumn{3}{|c|}{ Before 1997 Law Change } & \multicolumn{3}{|c|}{ After 1997 Law Change } \\
\hline & & $\begin{array}{c}\text { Born } \\
\text { Before Midnight }\end{array}$ & $\begin{array}{c}\text { Born } \\
\text { After Midnight }\end{array}$ & & $\begin{array}{c}\text { Born } \\
\text { Before Midnight }\end{array}$ & $\begin{array}{c}\text { Born } \\
\text { After Midnight }\end{array}$ & \\
\hline Variable & & Mean & Mean & p-value & Mean & Mean & p-value \\
\hline \multirow{5}{*}{$\begin{array}{l}\text { Length of } \\
\text { Stay }\end{array}$} & Raw Length of Stay & 1.99 & 1.23 & $(0.000)^{* *}$ & 2.29 & 1.58 & $(0.000)^{* *}$ \\
\hline & Additional Midnights & 0.99 & 1.23 & $(0.000)^{* *}$ & 1.29 & 1.58 & $(0.000)^{* *}$ \\
\hline & $>=1$ Additional Midnights & 0.57 & 0.73 & $(0.000)^{* *}$ & 0.82 & 0.91 & $(0.000)^{* *}$ \\
\hline & $>=2$ Additional Midnights & 0.11 & 0.17 & $(0.000)^{* *}$ & 0.15 & 0.32 & $(0.000)^{* *}$ \\
\hline & $>=3$ Additional Midnights & 0.06 & 0.08 & $(0.000)^{* *}$ & 0.07 & 0.09 & $(0.000)^{* *}$ \\
\hline \multirow{7}{*}{$\begin{array}{l}\text { Infant } \\
\text { Outcomes }\end{array}$} & 7-Day Readmission & 0.027 & 0.028 & $(0.428)$ & 0.028 & 0.027 & $(0.690)$ \\
\hline & 28-Day Readmission & 0.042 & 0.045 & $(0.047)^{*}$ & 0.047 & 0.046 & $(0.522)$ \\
\hline & 28-Day Readmission Charges & 852 & 938 & $(0.376)$ & 1128 & 1287 & $(0.346)$ \\
\hline & 1-year Readmission Charges & 1763 & 1868 & $(0.457)$ & 2189 & 2461 & $(0.246)$ \\
\hline & 28-Day Mortality & 0.0035 & 0.0036 & $(0.836)$ & 0.0028 & 0.0030 & $(0.829)$ \\
\hline & 1-year Mortality & 0.0056 & 0.0053 & $(0.687)$ & 0.0040 & 0.0042 & $(0.711)$ \\
\hline & Observations & 28898 & 29477 & & 16637 & 17283 & \\
\hline
\end{tabular}

Calculations from the "40 minute" sample includes births from 11:37pm-11:55pm \& 12:05am-12:24am. 28-day measures include outcomes 28 days from the midnight

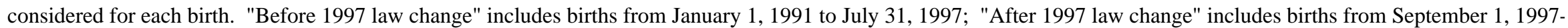

December 31, 2002. ** = significant at $1 \%$; * significant at $5 \%$. 
Table 2: Selected Characteristics: 40 Minutes Around Midnight Sample

\begin{tabular}{|c|c|c|c|c|}
\hline & & \multicolumn{3}{|c|}{$\underline{\text { All Years }}$} \\
\hline & & $\begin{array}{c}\text { Before } \\
\text { Midnight } \\
\end{array}$ & $\begin{array}{c}\text { After } \\
\text { Midnight } \\
\end{array}$ & p-value \\
\hline \multirow{5}{*}{$\begin{array}{l}\text { Pregnancy } \\
\text { Characteristics }\end{array}$} & At least one pregnancy complication & 0.585 & 0.589 & $(0.264)$ \\
\hline & $<9$ prenatal visits & 0.199 & 0.204 & $(0.052)$ \\
\hline & 9-15 prenatal visits & 0.695 & 0.689 & $(0.043)^{*}$ \\
\hline & $>15$ prenatal visits & 0.088 & 0.089 & $(0.655)$ \\
\hline & Prenatal visits missing & 0.019 & 0.019 & $(0.850)$ \\
\hline \multirow{8}{*}{$\begin{array}{l}\text { Mother's } \\
\text { Characteristics }\end{array}$} & Born in California & 0.390 & 0.391 & $(0.753)$ \\
\hline & Born outside U.S. & 0.472 & 0.475 & $(0.411)$ \\
\hline & 1st Birth & 0.400 & 0.394 & $(0.047)^{*}$ \\
\hline & Age & 26.82 & 26.79 & $(0.489)$ \\
\hline & High school drop out & 0.355 & 0.356 & $(0.652)$ \\
\hline & High school & 0.287 & 0.288 & $(0.684)$ \\
\hline & Some College & 0.184 & 0.181 & $(0.250)$ \\
\hline & College+ & 0.164 & 0.164 & $(0.907)$ \\
\hline \multirow{6}{*}{$\begin{array}{l}\text { Father's } \\
\text { Characteristics }\end{array}$} & Age & 29.755 & 29.725 & $(0.529)$ \\
\hline & High school drop out & 0.302 & 0.303 & $(0.848)$ \\
\hline & High school & 0.287 & 0.285 & $(0.465)$ \\
\hline & Some College & 0.156 & 0.155 & $(0.650)$ \\
\hline & College+ & 0.181 & 0.181 & $(0.898)$ \\
\hline & Missing education data & 0.075 & 0.078 & $(0.086)$ \\
\hline \multirow{5}{*}{$\begin{array}{l}\text { Newborn } \\
\text { Characteristics }\end{array}$} & Boy & 0.509 & 0.507 & $(0.530)$ \\
\hline & White & 0.544 & 0.537 & $(0.029)^{*}$ \\
\hline & African American & 0.065 & 0.066 & $(0.570)$ \\
\hline & Hispanic & 0.186 & 0.188 & $(0.443)$ \\
\hline & Asian & 0.092 & 0.094 & $(0.198)$ \\
\hline \multirow{9}{*}{$\begin{array}{l}\text { Birth } \\
\text { Characteristics }\end{array}$} & Birthweight $<2500$ grams & 0.048 & 0.047 & $(0.506)$ \\
\hline & Gestational age $>=37$ weeks & 0.909 & 0.906 & $(0.170)$ \\
\hline & Vaginal birth after C-section & 0.025 & 0.026 & $(0.353)$ \\
\hline & Forceps or vacuum & 0.099 & 0.095 & $(0.022)^{*}$ \\
\hline & Less than 3 hours & 0.018 & 0.019 & $(0.228)$ \\
\hline & More than 20 hours & 0.007 & 0.006 & $(0.310)$ \\
\hline & Labor stimulated & 0.119 & 0.115 & $(0.053)$ \\
\hline & Labor induced & 0.099 & 0.095 & $(0.065)$ \\
\hline & Admitted on a Weekend & 0.237 & 0.241 & $(0.141)$ \\
\hline \multirow[t]{4}{*}{ Primary Payer } & Medicaid & 0.463 & 0.463 & $(0.898)$ \\
\hline & Self pay/unknown & 0.041 & 0.039 & $(0.182)$ \\
\hline & Private & 0.480 & 0.482 & $(0.458)$ \\
\hline & Government & 0.223 & 0.227 & $(0.147)$ \\
\hline \multirow{3}{*}{$\begin{array}{l}\text { Hospital } \\
\text { Characteristics }\end{array}$} & Private nonprofit & 0.634 & 0.636 & $(0.554)$ \\
\hline & Private for-profit & 0.142 & 0.136 & $(0.012)^{*}$ \\
\hline & Observations & 45807 & 47046 & \\
\hline
\end{tabular}

Data are pooled 1991-2002. Calculations from the "40 minute" sample includes births from 11:37pm-11:55pm \& 12:05am-12:24am. Race and Ethnicity is not broken out separately after 1994. Prenatal visits is missing in approx. $2 \%$ of the cases. Mother's education is missing in approximately $1 \%$ of the cases. Full set of variables and separate time periods are listed in the appendix. $\quad * *=$ significant at $1 \%$; $*$ significant at $5 \%$. 
Table 3: Time of Birth and Length of Stay

\section{A. Before 1997 Law Change}

Dependent Variable:

Additional Midnights

\begin{tabular}{|c|c|c|c|c|c|}
\hline Model & $\begin{array}{c}\text { Local linear } \\
\text { (1) }\end{array}$ & $\begin{array}{c}\text { OLS } \\
(2)\end{array}$ & $\begin{array}{l}\text { OLS } \\
\text { (3) }\end{array}$ & $\begin{array}{c}\text { OLS } \\
(4)\end{array}$ & $\begin{array}{c}\text { OLS } \\
(5)\end{array}$ \\
\hline Birth After Midnight & $\begin{array}{c}0.273 \\
(0.036)\end{array}$ & $\begin{array}{c}0.293 \\
(0.033)\end{array}$ & $\begin{array}{c}0.272 \\
(0.032)\end{array}$ & $\begin{array}{c}0.220 \\
(0.0201)\end{array}$ & $\begin{array}{c}0.216 \\
(0.019)\end{array}$ \\
\hline Birth After Midnight * Minute from cutoff & & $\begin{array}{l}-0.001 \\
(0.002)\end{array}$ & $\begin{array}{l}-0.001 \\
(0.00)\end{array}$ & $\begin{array}{c}0.001 \\
(0.0005)\end{array}$ & $\begin{array}{c}0.001 \\
(0.0004)\end{array}$ \\
\hline Birth Prior to Midnight* Minute from cutoff & & $\begin{array}{l}-0.004 \\
(0.002)\end{array}$ & $\begin{array}{l}-0.003 \\
(0.002)\end{array}$ & $\begin{array}{c}0.001 \\
(0.0004)\end{array}$ & $\begin{array}{c}0.001 \\
(0.0004)\end{array}$ \\
\hline Full Controls & No & No & Yes & No & Yes \\
\hline Sample & 40 minute & 40 minute & 40 minute & 2 hour & 2hour \\
\hline Observations & 60398 & 58375 & 58375 & 162821 & 162821 \\
\hline Mean of Dep. Variable Before Midnight & 1.00 & 0.99 & 0.99 & 0.97 & 0.97 \\
\hline
\end{tabular}

\section{B. After 1997 Law Change}

Dependent Variable: Additional Midnights

\begin{tabular}{cccccc} 
Model: Local linear & OLS & OLS & OLS & OLS \\
& $(1)$ & $(2)$ & $(3)$ & $(4)$ & $(5)$ \\
& 0.255 & 0.238 & 0.230 & 0.252 & 0.246 \\
& $(0.045)$ & $(0.041)$ & $(0.039)$ & $(0.026)$ & $(0.025)$ \\
\cline { 2 - 6 } cutoff & & 0.006 & 0.006 & 0.001 & 0.001 \\
& & $(0.003)$ & $(0.002)$ & $(0.0006)$ & $(0.0005)$ \\
\cline { 2 - 6 } cutoff & & -0.001 & -0.001 & 0.001 & 0.001 \\
& & $(0.0023)$ & $(0.003)$ & $(0.0006)$ & $(0.0006)$ \\
\cline { 2 - 6 } & No & No & Yes & No & Yes \\
& 40 minute & 40 minute & 40 minute & 2 hour & 2 hour \\
& 35736 & 33920 & 33920 & 94879 & 94879 \\
& 1.30 & 1.29 & 1.29 & 1.28 & 1.28 \\
\hline
\end{tabular}

Mean of Dep. Variable Before Midnight

(5) consider the "two hour" sample from 11:02pm-11:55pm \& 12:05am to 12:59am. Column (1) reports the

difference in local linear regression estimates just above and below the discontinuity using a triangle kernel and a

bandwidth of 20 minutes. Asymptotic standard errors in parentheses. Columns (2)-(5) report OLS results using

different samples close to the midnight cutoff, along with linear trends in the time of birth before and after

midnight; robust standard errors reported in parentheses. Full controls include the controls listed in Appendix

Table A1, as well as indicators for the mother's age, the father's age, the year of birth and the month of birth. 
Table 4: Time of Birth and Infant Readmissions

A. Dependent Variable: 7-Day Readmission

\begin{tabular}{|c|c|c|c|c|c|c|c|c|}
\hline \multirow[b]{2}{*}{ Model: } & \multicolumn{4}{|c|}{ Before 1997 Law Change } & \multicolumn{4}{|c|}{ After 1997 Law Change } \\
\hline & $\begin{array}{c}\text { Local linear } \\
(1) \\
\end{array}$ & $\begin{array}{c}\text { Probit } \\
(2)\end{array}$ & $\begin{array}{c}\text { Probit } \\
(3)\end{array}$ & $\begin{array}{c}\text { Probit } \\
(4)\end{array}$ & $\begin{array}{c}\text { Local linear } \\
\text { (5) }\end{array}$ & $\begin{array}{c}\text { Probit } \\
(6)\end{array}$ & $\begin{array}{c}\text { Probit } \\
(7)\end{array}$ & $\begin{array}{c}\text { Probit } \\
(8)\end{array}$ \\
\hline Birth After Midnight & $\begin{array}{l}0.00038 \\
(0.0028) \\
\end{array}$ & $\begin{array}{l}0.00188 \\
(0.0028) \\
\end{array}$ & $\begin{array}{l}0.00174 \\
(0.0025) \\
\end{array}$ & $\begin{array}{l}0.00134 \\
(0.0015) \\
\end{array}$ & $\begin{array}{l}0.00040 \\
(0.0038) \\
\end{array}$ & $\begin{array}{r}-0.00052 \\
(0.0036) \\
\end{array}$ & $\begin{array}{c}-0.00035 \\
(0.0032) \\
\end{array}$ & $\begin{array}{l}0.00142 \\
(0.0020) \\
\end{array}$ \\
\hline Birth After Midnight * Minute from cutoff & & $\begin{array}{l}0.00018 \\
(0.0002)\end{array}$ & $\begin{array}{l}0.00018 \\
(0.0002) \\
\end{array}$ & $\begin{array}{c}-0.00001 \\
(0.00003) \\
\end{array}$ & & $\begin{array}{l}0.00002 \\
(0.0002)\end{array}$ & $\begin{array}{l}0.00000 \\
(0.0002) \\
\end{array}$ & $\begin{array}{c}-0.00001 \\
(0.00004) \\
\end{array}$ \\
\hline Birth Prior to Midnight* Minute from cutoff & & $\begin{array}{c}-0.00026 \\
(0.0002) \\
\end{array}$ & $\begin{array}{c}-0.00023 \\
(0.0002) \\
\end{array}$ & $\begin{array}{c}0.00003 \\
(0.00003) \\
\end{array}$ & & $\begin{array}{c}-0.00004 \\
(0.0002) \\
\end{array}$ & $\begin{array}{c}-0.00004 \\
(0.0002) \\
\end{array}$ & $\begin{array}{c}-0.00004 \\
(0.00005) \\
\end{array}$ \\
\hline Full Controls & No & No & Yes & Yes & No & No & Yes & Yes \\
\hline Sample & 40 minute & 40 minute & 40 minute & 2 hour & 40 minute & 40 minute & 40 minute & 2hour \\
\hline Observations & 60398 & 58365 & 58365 & 162791 & 35736 & 33920 & 33920 & 94879 \\
\hline Mean of Dep. Variable Before Midnight & 0.027 & 0.027 & 0.027 & 0.026 & 0.028 & 0.028 & 0.028 & 0.029 \\
\hline
\end{tabular}

\section{B. Dependent Variable: 28-Day Readmission}

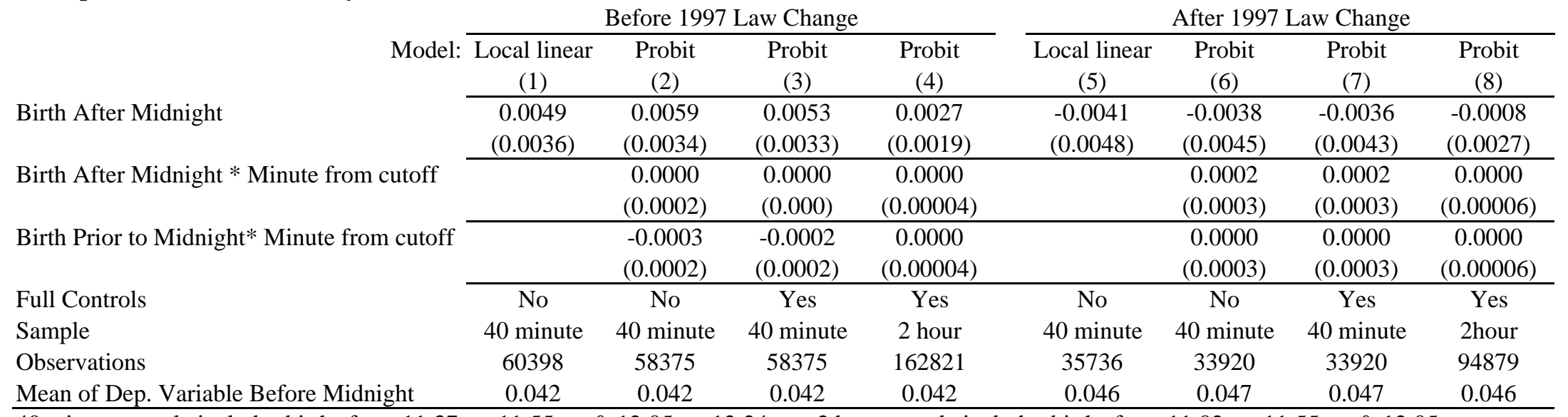

40 minute sample includes births from 11:37pm-11:55pm \& 12:05am-12:24am; 2 hour sample includes births from 11:02pm-11:55pm \& 12:05am to

12:59am. Columns (1) and (5) report the difference in local linear regression estimates just above and below the discontinuity using a triangle kernel and a bandwidth of 20 minutes. Asymptotic standard errors in parentheses. Columns (2)-(4) and (6)-(8) report marginal effects evaluated at the mean of the covariates with robust standard errors reported in parentheses. Full controls include the controls listed in Appendix Table A1, as well as indicators for the mother's age, the father's age, the year of birth and the month of birth. 
Table 5: Time of Birth and Infant Mortality

\section{A. Dependent Variable: 28-day mortality}

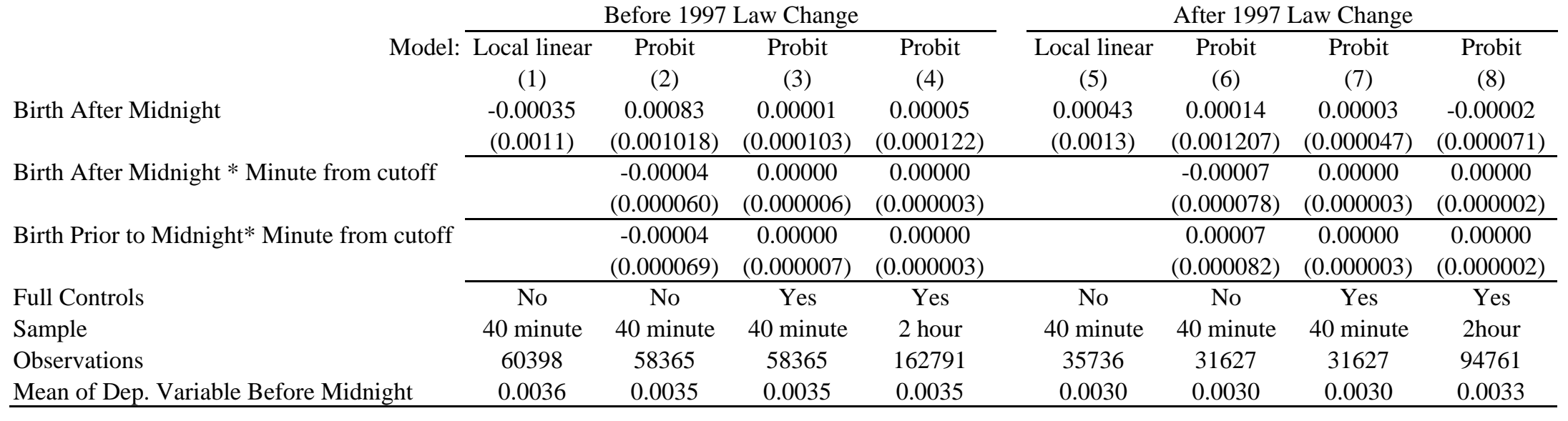

\section{B. Dependent Variable: 1-year mortality}

\begin{tabular}{|c|c|c|c|c|c|c|c|c|}
\hline \multirow{2}{*}{ D. } & \multicolumn{4}{|c|}{ Before 1997 Law Change } & \multicolumn{4}{|c|}{ After 1997 Law Change } \\
\hline & $\begin{array}{c}\text { Local linear } \\
\text { (1) }\end{array}$ & $\begin{array}{l}\text { Probit } \\
(2)\end{array}$ & $\begin{array}{l}\text { Probit } \\
\text { (3) }\end{array}$ & $\begin{array}{c}\text { Probit } \\
\text { (4) }\end{array}$ & $\begin{array}{c}\text { Local linear } \\
\text { (5) }\end{array}$ & $\begin{array}{l}\text { Probit } \\
(6)\end{array}$ & $\begin{array}{l}\text { Probit } \\
(7)\end{array}$ & $\begin{array}{c}\text { Probit } \\
(8)\end{array}$ \\
\hline Birth After Midnight & 0.000003 & 0.00127 & 0.00026 & 0.00001 & 0.00083 & 0.00077 & 0.00028 & 0.00002 \\
\hline \multirow[t]{2}{*}{ Birth After Midnight * Minute from cutoff } & & -0.00008 & -0.00001 & 0.00000 & & -0.00002 & -0.00001 & 0.00001 \\
\hline & & $(0.000076)$ & $(0.000029)$ & $(0.000008)$ & & $(0.000087)$ & $(0.000018)$ & $(0.000007)$ \\
\hline Birth Prior to Midnight* Minute from cutoff & & -0.00008 & -0.00003 & 0.00000 & & -0.00003 & -0.00002 & -0.00001 \\
\hline Full Controls & No & No & Yes & Yes & No & No & Yes & Yes \\
\hline Sample & 40 minute & 40 minute & 40 minute & 2 hour & 40 minute & 40 minute & 40 minute & 2hour \\
\hline Observations & 60398 & 58365 & 58365 & 162791 & 35736 & 33157 & 33157 & 94761 \\
\hline Mean of Dep. Variable Before Midnight & 0.0058 & 0.0056 & 0.0056 & 0.0055 & 0.0043 & 0.0041 & 0.0041 & 0.0048 \\
\hline
\end{tabular}

40 minute sample includes births from 11:37pm-11:55pm \& 12:05am-12:24am; 2 hour sample includes births from 11:02pm-11:55pm \& 12:05am to

12:59am. Columns (1) and (5) report the difference in local linear regression estimates just above and below the discontinuity using a triangle kernel and a bandwidth of 20 minutes. Asymptotic standard errors in parentheses. Columns (2)-(4) and (6)-(8) report marginal effects evaluated at the mean of the covariates with robust standard errors reported in parentheses. Full controls include the controls listed in Appendix Table A1, as well as indicators for the mother's age, the father's age, the year of birth and the month of birth. 
Table 6: Maternal Length of Stay \& Outcomes

Birth After Midnight

Birth After Midnight* Minute from cutoff

Birth Prior to Midnight* Minute from cutoff

Observations

Dependent Variable:

\begin{tabular}{cc}
\multicolumn{2}{c}{ Before 1997 Law Change } \\
\hline Additional & 28-Day \\
Midnights & Readmission
\end{tabular}

\begin{tabular}{ccccc}
\multicolumn{2}{c}{ Before 1997 Law Change } & & \multicolumn{2}{c}{ After 1997 Law Change } \\
\cline { 1 - 2 } \cline { 5 - 5 } $\begin{array}{c}\text { Additional } \\
\text { Midnights }\end{array}$ & $\begin{array}{c}\text { 28-Day } \\
\text { Readmission }\end{array}$ & & $\begin{array}{c}\text { Additional } \\
\text { Midnights }\end{array}$ & $\begin{array}{c}\text { 28-Day } \\
\text { Readmission }\end{array}$ \\
\hline 0.297 & $(2)$ & & $(3)$ & $(4)$ \\
$(0.086)$ & -0.0006 & & 0.229 & 0.0015 \\
\hline 0.0004 & $(0.0012)$ & & $(0.045)$ & $(0.0015)$ \\
$(0.0077)$ & $(0.00007)$ & & $(0.0020)$ & -0.00004 \\
\hline-0.0008 & 0.0000 & 0.0022 & $-0.0001)$ \\
$(0.0025)$ & $(0.00008)$ & & $(0.0018)$ & $(0.00009)$ \\
\hline 57599 & 57597 & 33560 & 32869 \\
0.685 & 0.008 & 0.968 & 0.008 \\
\hline
\end{tabular}

Mean of Dep. Variable Before Midnight

Analyses uses the "40 minute" sample, which includes births from 11:37pm-11:55pm \& 12:05am to 12:24am. Columns (1) and (3) are estimated with by OLS, and Columns (2) and (4) report estimates that are marginal effects from a probit model, evaluated at the mean of the covariates. All models include full controls. Robust standard errors reported in parentheses. 
Table A1: Table of Means

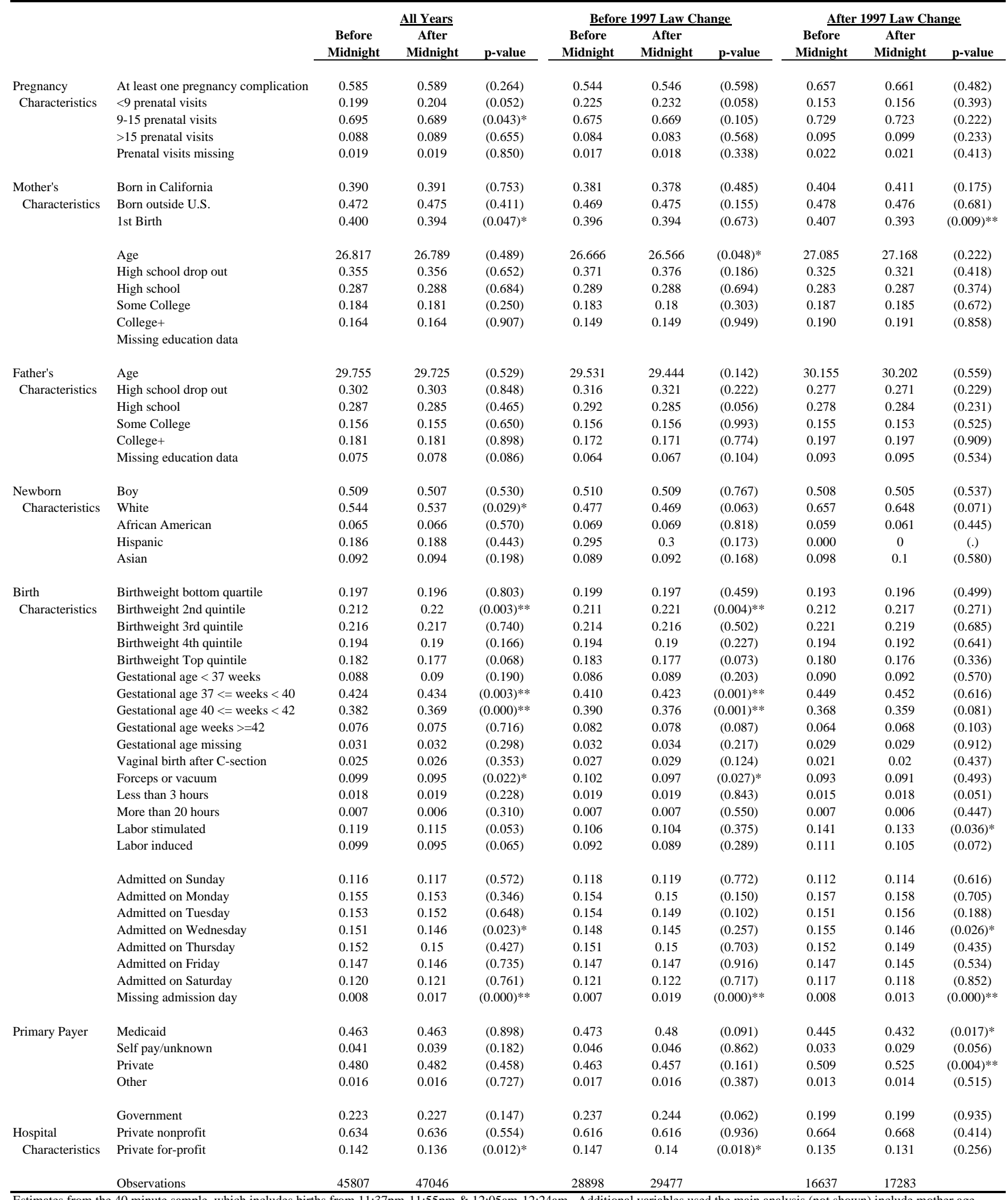

Estimates from the 40 minute sample, which includes births from 11:37pm-11:55pm \& 12:05am-12:24am. Additional variables used the main analysis (not shown) include mother age indicators, father age indicators, year of birth indicators and month of birth indicators. $* *=$ significant at $1 \%$; $*=$ significant at $5 \%$. 
Table A2: Selected Covariates: 40 Minute Pooled Sample, 1991-2002

\begin{tabular}{|c|c|c|c|c|}
\hline & Dependent Variable: & $\begin{array}{l}\text { Additional Midnights } \\
\text { (1) }\end{array}$ & $\begin{array}{c}\text { 28-Day Readmission } \\
\text { (2) }\end{array}$ & $\begin{array}{c}\text { 1-year Mortality } \\
\text { (3) }\end{array}$ \\
\hline & \multirow[t]{2}{*}{ Birth After Midnight } & 0.255 & 0.0023 & 0.00036 \\
\hline & & $(0.025)^{* *}$ & $(0.0026)$ & $(0.00035)$ \\
\hline & \multirow[t]{2}{*}{ Birth After Midnight * Minute from cutoff } & 0.001 & 0.0001 & -0.00001 \\
\hline & & $(0.002)$ & $(0.0002)$ & $(0.00002)$ \\
\hline & \multirow[t]{2}{*}{ Birth Prior to Midnight* Minute from cutof1 } & -0.002 & -0.0001 & -0.00003 \\
\hline & & $(0.002)$ & $(0.0002)$ & $(0.00002)$ \\
\hline Pregnancy & \multirow[t]{2}{*}{ At least one pregnancy complication } & 0.021 & -0.0006 & 0.00050 \\
\hline Characterisitics & & $(0.014)$ & $(0.0014)$ & $(0.00018)^{* *}$ \\
\hline & \multirow[t]{2}{*}{ 9-15 prenatal visits } & -0.073 & -0.0022 & -0.00217 \\
\hline \multirow[t]{5}{*}{ ( $<9$ omitted) } & & $(0.020)^{* *}$ & $(0.0017)$ & $(0.00029)^{* *}$ \\
\hline & \multirow[t]{2}{*}{$>15$ prenatal visits } & 0.055 & 0.0019 & -0.00107 \\
\hline & & $(0.029)$ & $(0.0027)$ & $(0.00018)^{* *}$ \\
\hline & \multirow[t]{2}{*}{ Prenatal visits missing } & 0.060 & 0.0042 & -0.00014 \\
\hline & & $(0.060)$ & $(0.0051)$ & $(0.00044)$ \\
\hline \multirow{6}{*}{$\begin{array}{l}\text { Mother's } \\
\text { Characteristics }\end{array}$} & \multirow[t]{2}{*}{ Born in California } & 0.023 & 0.0005 & 0.00011 \\
\hline & & $(0.021)$ & $(0.0021)$ & $(0.00026)$ \\
\hline & \multirow[t]{2}{*}{ Born outside U.S. } & 0.028 & -0.0047 & -0.00075 \\
\hline & & $(0.023)$ & $(0.0024)^{*}$ & $(0.00029)^{*}$ \\
\hline & \multirow[t]{2}{*}{ 1st Birth } & 0.232 & 0.0063 & 0.00004 \\
\hline & & $(0.016)^{* *}$ & $(0.0016)^{* *}$ & $(0.00020)$ \\
\hline \multirow[t]{6}{*}{ (Age $<18$ omitted) } & \multirow[t]{2}{*}{ Age $=20$} & -0.057 & 0.0028 & 0.00121 \\
\hline & & $(0.046)$ & $(0.0047)$ & $(0.00090)$ \\
\hline & \multirow[t]{2}{*}{ Age $=30$} & 0.219 & 0.0026 & 0.00094 \\
\hline & & $(0.053)^{* *}$ & $(0.0051)$ & $(0.00092)$ \\
\hline & \multirow[t]{2}{*}{ Age $=40$} & 0.315 & 0.0119 & 0.00028 \\
\hline & & $(0.071)^{* *}$ & $(0.0075)$ & $(0.00091)$ \\
\hline \multirow[t]{8}{*}{ (College + omitted) } & \multirow[t]{2}{*}{ High school drop out } & 0.034 & 0.0011 & 0.00028 \\
\hline & & $(0.027)$ & $(0.0031)$ & $(0.00042)$ \\
\hline & \multirow[t]{2}{*}{ High school } & 0.004 & -0.0005 & -0.00012 \\
\hline & & $(0.023)$ & $(0.0027)$ & $(0.00034)$ \\
\hline & \multirow[t]{2}{*}{ Some College } & 0.009 & 0.0013 & 0.00018 \\
\hline & & $(0.021)$ & $(0.0026)$ & $(0.00037)$ \\
\hline & Missing education data & 0.147 & 0.0016 & 0.00220 \\
\hline & & $(0.091)$ & $(0.0074)$ & $(0.00174)$ \\
\hline Father's & Age $=20$ & 0.080 & 0.0071 & -0.00043 \\
\hline Characterisitcs & & $(0.076)$ & $(0.0084)$ & $(0.00057)$ \\
\hline & Age $=30$ & 0.083 & 0.0041 & -0.00042 \\
\hline (Age $<18$ omitted) & & $(0.074)$ & $(0.0080)$ & $(0.00058)$ \\
\hline & Age $=40$ & 0.183 & 0.0055 & -0.00071 \\
\hline & & $(0.075)^{*}$ & $(0.0080)$ & $(0.00046)$ \\
\hline & Age Missing & 0.203 & 0.0044 & -0.00021 \\
\hline & & $(0.075)^{* *}$ & $(0.0076)$ & $(0.00065)$ \\
\hline & High school drop out & 0.007 & -0.0026 & 0.00013 \\
\hline (College + omitted & & $(0.026)$ & $(0.0029)$ & $(0.00039)$ \\
\hline & High school & 0.014 & -0.0030 & -0.00017 \\
\hline & & $(0.023)$ & $(0.0025)$ & $(0.00033)$ \\
\hline & Some College & -0.038 & 0.0019 & 0.00025 \\
\hline & & $(0.021)$ & $(0.0026)$ & $(0.00037)$ \\
\hline & Missing education data & 0.052 & 0.0014 & -0.00037 \\
\hline & & $(0.044)$ & $(0.0040)$ & $(0.00038)$ \\
\hline & Mean of Dependent Variable & 1.10 & 0.044 & 0.0050 \\
\hline & Observations & 92853 & 92853 & 92802 \\
\hline
\end{tabular}

Additional characteristics included month, year, day of the week, mother's age, and father's age indicators. $* *=$ significant at $1 \%$; $*$ significant at $5 \%$. 
Table A2 (continued): Selected Covariates: 40 Minute Pooled Sample, 1991-2002

\begin{tabular}{|c|c|c|c|c|}
\hline & Dependent Variable: & $\begin{array}{l}\text { : Additional Midnights } \\
\text { (1) }\end{array}$ & $\begin{array}{c}\text { 28-Day Readmission } \\
(2)\end{array}$ & $\begin{array}{c}\text { 1-year Mortality } \\
\text { (3) }\end{array}$ \\
\hline \multirow{10}{*}{$\begin{array}{l}\text { Newborn } \\
\text { Characterisitcs }\end{array}$} & Boy & 0.095 & 0.0090 & 0.00043 \\
\hline & & $(0.013)^{* *}$ & $(0.0013)^{* *}$ & $(0.00017)^{*}$ \\
\hline & White & -0.070 & -0.0018 & 0.00048 \\
\hline & & $(0.022)^{* *}$ & $(0.0022)$ & $(0.00032)$ \\
\hline & African American & 0.148 & -0.0061 & 0.00089 \\
\hline & & $(0.038) * *$ & $(0.0030)^{*}$ & $(0.00062)$ \\
\hline & Hispanic & -0.024 & -0.0032 & -0.00024 \\
\hline & & $(0.029)$ & $(0.0028)$ & $(0.00036)$ \\
\hline & Asian & -0.058 & 0.0011 & 0.00060 \\
\hline & & $(0.030)$ & $(0.0031)$ & $(0.00057)$ \\
\hline \multirow{8}{*}{$\begin{array}{l}\text { Birth } \\
\text { Characterisitics }\end{array}$} & Birthweight 2nd quintile & -0.747 & -0.0090 & -0.00167 \\
\hline & & $(0.023)^{* *}$ & $(0.0018)^{* *}$ & $(0.00018)^{* *}$ \\
\hline & Birthweight 3rd quintile & -0.732 & -0.0115 & -0.00187 \\
\hline & & $(0.023)^{* *}$ & $(0.0018)^{* *}$ & $(0.00019)^{* *}$ \\
\hline & Birthweight 4th quintile & -0.718 & -0.0108 & -0.00197 \\
\hline & & $(0.023)^{* *}$ & $(0.0019)^{* *}$ & $(0.00020)^{* *}$ \\
\hline & Birthweight Top quintile & -0.636 & -0.0106 & -0.00169 \\
\hline & & $(0.024)^{* *}$ & $(0.0019)^{* *}$ & $(0.00019)^{* *}$ \\
\hline \multirow{20}{*}{$\begin{array}{l}\text { (Gestational } \\
\text { Age }<37 \text { weeks } \\
\text { omitted) }\end{array}$} & Gestational age $37<=$ weeks $<40$ & -1.511 & -0.0251 & -0.00366 \\
\hline & & $(0.049) * *$ & $(0.0020)^{* *}$ & $(0.00035)^{* *}$ \\
\hline & Gestational age $40<=$ weeks $<42$ & -1.500 & -0.0303 & -0.00301 \\
\hline & & $(0.048)^{* *}$ & $(0.0020)^{* *}$ & $(0.00031)^{* *}$ \\
\hline & Gestational age weeks $>=42$ & -1.465 & -0.0259 & -0.00145 \\
\hline & & $(0.051)^{* *}$ & $(0.0018)^{* *}$ & $(0.00016)^{* *}$ \\
\hline & Gestational age missing & -1.472 & -0.0214 & -0.00117 \\
\hline & & $(0.056)^{* *}$ & $(0.0025)^{* *}$ & $(0.00017)^{* *}$ \\
\hline & Vaginal birth after C-section & 0.058 & 0.0068 & -0.00021 \\
\hline & & $(0.040)$ & $(0.0046)$ & $(0.00046)$ \\
\hline & Forceps or vacuum & 0.109 & 0.0088 & -0.00054 \\
\hline & & $(0.021)^{* *}$ & $(0.0025)^{* *}$ & $(0.00027)^{*}$ \\
\hline & Less than 3 hours & -0.018 & 0.0035 & 0.00049 \\
\hline & & $(0.056)$ & $(0.0051)$ & $(0.00064)$ \\
\hline & More than 20 hours & 0.262 & 0.0062 & 0.00199 \\
\hline & & $(0.086)^{* *}$ & $(0.0084)$ & $(0.00162)$ \\
\hline & Labor stimulated & 0.003 & -0.0007 & -0.00060 \\
\hline & & $(0.020)$ & $(0.0021)$ & $(0.00022)^{* *}$ \\
\hline & Labor induced & -0.029 & 0.0042 & 0.00009 \\
\hline & & $(0.021)$ & $(0.0024)$ & $(0.00031)$ \\
\hline \multirow[t]{4}{*}{ (Sat. omitted) } & Admitted on Wednesday & 0.061 & 0.0010 & -0.00049 \\
\hline & & $(0.025)^{*}$ & $(0.0026)$ & $(0.00027)$ \\
\hline & Missing admission day & 0.148 & 0.0045 & 0.00139 \\
\hline & & $(0.067)^{*}$ & $(0.0065)$ & $(0.00111)$ \\
\hline \multirow{6}{*}{$\begin{array}{l}\text { Primary Payer } \\
\text { (private omitted) }\end{array}$} & Medicaid & 0.143 & 0.0102 & 0.00057 \\
\hline & & $(0.017)^{* *}$ & $(0.0018)^{* *}$ & $(0.00024)^{*}$ \\
\hline & Self pay/unknown & -0.250 & -0.0138 & 0.00016 \\
\hline & & $(0.031)^{* *}$ & $(0.0030)^{* *}$ & $(0.00047)$ \\
\hline & Other & 0.315 & -0.0012 & 0.00002 \\
\hline & & $(0.072)^{* *}$ & $(0.0055)$ & $(0.00076)$ \\
\hline \multirow{6}{*}{$\begin{array}{l}\text { Hospital } \\
\text { Characterisitcs } \\
\text { (for-profit } \\
\text { omitted) }\end{array}$} & Government & 0.439 & -0.0018 & 0.00035 \\
\hline & & $(0.020)^{* *}$ & $(0.0022)$ & $(0.00035)$ \\
\hline & Private nonprofit & 0.080 & -0.0041 & 0.00035 \\
\hline & & $(0.016)^{* *}$ & $(0.0020)^{*}$ & $(0.00026)$ \\
\hline & Mean of Dependent Variable & 1.10 & 0.044 & 0.0050 \\
\hline & Observations & 92853 & 92853 & 92802 \\
\hline
\end{tabular}


Appendix Table A3: Infant Outcomes Across Patient Groups

\begin{tabular}{|c|c|c|c|c|c|c|c|c|c|c|}
\hline & \multicolumn{3}{|c|}{ Additional Midnights } & \multicolumn{3}{|c|}{ 28-Day Readmission } & \multicolumn{4}{|c|}{ 1-year Mortality } \\
\hline & $\begin{array}{c}\text { Coeff. On } \\
\text { After Midnight } \\
\end{array}$ & S.E. & $\begin{array}{l}\text { Mean of } \\
\text { Dep. Var. }\end{array}$ & $\begin{array}{c}\text { Marginal effect of } \\
\text { After Midnight }\end{array}$ & S.E. & $\begin{array}{l}\text { Mean of } \\
\text { Dep. Var. }\end{array}$ & $\begin{array}{c}\text { Marginal effect of } \\
\text { After Midnight }\end{array}$ & S.E. & $\begin{array}{l}\text { Mean of } \\
\text { Dep. Var. }\end{array}$ & Obs. \\
\hline Subgroup: & & & & & & & & & & \\
\hline Medicaid Patient & 0.25831 & $(0.02984)^{* *}$ & 1.10 & 0.00414 & $(0.00294)$ & 0.047 & -0.00013 & $(0.00054)$ & 0.0062 & 77272 \\
\hline Unmarried & 0.25165 & $(0.0360)^{* *}$ & 1.09 & 0.00146 & $(.000332)$ & 0.044 & 0.00017 & $(0.00063)$ & 0.0060 & 56440 \\
\hline For-Profit Hospital & 0.23857 & $(0.03859)^{* *}$ & 0.79 & -0.00138 & $(0.00493)$ & 0.044 & 0.00009 & $(0.00039)$ & 0.0041 & 19765 \\
\hline Cesarean Section & 0.23909 & $(0.06236)^{* *}$ & 2.87 & 0.00376 & $(0.00428)$ & 0.049 & -0.00208 & $(0.00089)^{*}$ & 0.0094 & 34442 \\
\hline Birthweight $<3000$ g & 0.22649 & $(0.07206)^{* *}$ & 1.71 & 0.00654 & $(0.00479)$ & 0.060 & -0.00024 & $(0.00148)$ & 0.0183 & 34675 \\
\hline High P(Readmission|X) & 0.21937 & $(0.03615)^{* *}$ & 1.25 & 0.00285 & $(0.00318)$ & 0.055 & 0.00019 & $(0.00060)$ & 0.00944 & 77012 \\
\hline Low P(Readmission|X) & 0.21634 & $(0.01584)^{* *}$ & 0.72 & 0.00264 & $(0.00237)$ & 0.031 & -0.00022 & $(0.00039)$ & 0.00191 & 85319 \\
\hline Low Maternal Education & 0.18903 & $(0.03297)^{* *}$ & 1.07 & 0.00375 & $(0.00317)$ & 0.043 & -0.00065 & $(0.00063)$ & 0.0060 & 60403 \\
\hline Kaiser Hospital & 0.18820 & $(0.05150)^{* *}$ & 0.91 & 0.00768 & $(0.00510)$ & 0.035 & 0.0005 & $(0.00062)$ & 0.0062 & 19616 \\
\hline Any Labor Complication & 0.18372 & $(0.02364)^{* *}$ & 0.97 & 0.00549 & $(0.00236)^{*}$ & 0.042 & 0.00018 & $(0.00039)$ & 0.0060 & 108265 \\
\hline Scheduled Birth & 0.16825 & $(0.05151)^{* *}$ & 0.75 & -0.00064 & $(0.00608)$ & 0.049 & 0.00008 & $(0.00021)$ & 0.0037 & 15225 \\
\hline Any Pregnancy Complication & 0.16427 & $(0.02678)^{* *}$ & 0.98 & 0.00455 & $(0.00263)$ & 0.044 & 0.00030 & $(0.00045)$ & 0.0063 & 88955 \\
\hline All Data & 0.13561 & $(0.05248)^{* *}$ & 1.81 & 0.00210 & $(0.00163)$ & 0.043 & -0.00025 & $(0.00033)$ & 0.0065 & 229554 \\
\hline
\end{tabular}

B. After the Law Change

\begin{tabular}{|c|c|c|c|c|c|c|c|c|c|c|}
\hline \multirow{3}{*}{ Subgroup: } & \multicolumn{3}{|c|}{ Additional Midnights } & \multicolumn{3}{|c|}{ 28-Day Readmission } & \multicolumn{4}{|c|}{ 1-year Mortality } \\
\hline & \multirow{2}{*}{$\begin{array}{c}\text { Coeff. On } \\
\text { After Midnight } \\
\end{array}$} & \multirow[t]{2}{*}{ S.E. } & \multirow[t]{2}{*}{$\begin{array}{l}\text { Mean of } \\
\text { Dep. Var. }\end{array}$} & \multirow[t]{2}{*}{$\begin{array}{c}\text { Coeff. On } \\
\text { After Midnight }\end{array}$} & \multirow[t]{2}{*}{ S.E. } & \multirow[t]{2}{*}{$\begin{array}{c}\text { Mean of } \\
\text { Dep. Var. }\end{array}$} & $\begin{array}{c}\text { Coeff. On } \\
\text { After Midnight } \\
\end{array}$ & \multicolumn{3}{|c|}{$\begin{array}{l}\text { Mean of } \\
\text { Dep. Var. }\end{array}$} \\
\hline & & & & & & & & & & \\
\hline Medicaid Patient & 0.26693 & $(0.03925)^{* *}$ & 1.35 & 0.00464 & $(0.00415)$ & 0.049 & 0.00027 & $(0.00046)$ & 0.0051 & 41412 \\
\hline Unmarried & 0.24456 & $(0.07785)^{* *}$ & 1.28 & 0.00486 & $(0.00735)$ & 0.050 & -0.00019 & $(0.00032)$ & 0.0076 & 6374 \\
\hline For-Profit Hospital & 0.31748 & $(0.05329)^{* *}$ & 1.07 & -0.00175 & $(0.00661)$ & 0.052 & -0.00021 & $(0.00027)$ & 0.0086 & 5547 \\
\hline Cesarean Section & 0.22570 & $(0.08319)^{* *}$ & 3.14 & 0.00909 & $(0.00570)$ & 0.052 & -0.00027 & $(0.00083)$ & 0.0074 & 20777 \\
\hline Birthweight $<3000$ g & 0.09485 & $(0.09228)$ & 2.05 & 0.00836 & $(0.00636)$ & 0.063 & -0.00026 & $(0.00129)$ & 0.0168 & 19937 \\
\hline High P(Readmission|X) & 0.26061 & $(0.04092)^{* *}$ & 1.49 & -0.00017 & $(0.00397)$ & 0.057 & -0.00026 & $(0.00037)$ & 0.00756 & 51520 \\
\hline Low P(Readmission|X) & 0.22471 & $(0.02251)^{* *}$ & 1.01 & -0.00214 & $(0.00332)$ & 0.033 & 0.00077 & $(0.00052)$ & 0.00226 & 27239 \\
\hline Low Maternal Education & 0.24245 & $(0.04515)^{* *}$ & 1.29 & 0.00656 & $(0.00459)$ & 0.045 & 0.00061 & $(0.00042)$ & 0.0044 & 29431 \\
\hline Kaiser Hospital & 0.08651 & $(0.05824)$ & 1.15 & -0.00559 & $(0.00538)$ & 0.034 & -0.000002 & $(0.00014)$ & 0.0057 & 11176 \\
\hline Any Labor Complication & 0.24057 & $(0.02893)^{* *}$ & 1.27 & -0.00004 & $(0.00305)$ & 0.046 & 0.00010 & $(0.00031)$ & 0.0050 & 69767 \\
\hline Scheduled Birth & 0.27764 & $(0.04104)^{* *}$ & 1.21 & 0.00201 & $(0.00419)$ & 0.041 & 0.00050 & $(0.00044)$ & 0.0038 & 30303 \\
\hline Any Pregnancy Complication & 0.23126 & $(0.03095)^{* *}$ & 1.28 & -0.00033 & $(0.00325)$ & 0.048 & 0.00001 & $(0.00037)$ & 0.0055 & 62285 \\
\hline All Data & 0.29971 & $(0.06152)^{* *}$ & 2.10 & 0.00020 & $(0.00196)$ & 0.045 & 0.00029 & $(0.00031)$ & 0.0055 & 162427 \\
\hline
\end{tabular}


Appendix Table A4: Characteristics of Compliers

\begin{tabular}{|c|c|c|c|c|c|c|c|}
\hline & & \multicolumn{3}{|c|}{ Before Law Change } & \multicolumn{3}{|c|}{ After Law Change } \\
\hline & & \multicolumn{2}{|c|}{ 40-minute Sample } & \multirow{2}{*}{$\begin{array}{c}\text { 24-hour } \\
\text { Population } \\
\text { Mean } \\
\end{array}$} & \multicolumn{2}{|c|}{ 40-minute Sample } & \multirow{2}{*}{$\begin{array}{c}\text { 24-hour } \\
\text { Population } \\
\text { Mean } \\
\end{array}$} \\
\hline & & $\begin{array}{c}\text { Complier } \\
\text { Mean }\end{array}$ & $\begin{array}{c}\text { Overall } \\
\text { Mean }\end{array}$ & & $\begin{array}{c}\text { Complier } \\
\text { Mean }\end{array}$ & $\begin{array}{c}\text { Overall } \\
\text { Mean }\end{array}$ & \\
\hline \multirow{5}{*}{$\begin{array}{l}\text { Pregnancy } \\
\text { Characteristics }\end{array}$} & At least one pregnancy complication & 0.546 & 0.545 & 0.565 & 0.683 & 0.659 & 0.664 \\
\hline & $<9$ prenatal visits & 0.202 & 0.228 & 0.208 & 0.129 & 0.155 & 0.137 \\
\hline & 9-15 prenatal visits & 0.699 & 0.672 & 0.685 & 0.696 & 0.726 & 0.734 \\
\hline & $>15$ prenatal visits & 0.078 & 0.083 & 0.091 & 0.147 & 0.097 & 0.109 \\
\hline & Prenatal visits missing & 0.021 & 0.017 & 0.016 & 0.028 & 0.021 & 0.021 \\
\hline \multirow{9}{*}{$\begin{array}{l}\text { Mother's } \\
\text { Characteristics }\end{array}$} & Born in California & 0.380 & 0.380 & 0.391 & 0.396 & 0.407 & 0.414 \\
\hline & Born outside U.S. & 0.482 & 0.472 & 0.455 & 0.490 & 0.476 & 0.460 \\
\hline & 1st Birth & 0.385 & 0.395 & 0.391 & 0.414 & 0.400 & 0.387 \\
\hline & Age & 26.2 & 26.6 & 27.1 & 28.3 & 27.1 & 27.8 \\
\hline & High school drop out & 0.387 & 0.374 & 0.346 & 0.297 & 0.323 & 0.298 \\
\hline & High school & 0.274 & 0.289 & 0.291 & 0.237 & 0.285 & 0.282 \\
\hline & Some College & 0.177 & 0.181 & 0.191 & 0.198 & 0.186 & 0.193 \\
\hline & College+ & 0.156 & 0.149 & 0.165 & 0.252 & 0.191 & 0.213 \\
\hline & Missing education data & 0.006 & 0.007 & 0.007 & 0.015 & 0.015 & 0.014 \\
\hline \multirow{6}{*}{$\begin{array}{l}\text { Father's } \\
\text { Characteristics }\end{array}$} & Age & 28.9 & 29.5 & 29.9 & 31.4 & 30.2 & 30.7 \\
\hline & High school drop out & 0.312 & 0.319 & 0.299 & 0.232 & 0.274 & 0.256 \\
\hline & High school & 0.259 & 0.289 & 0.290 & 0.253 & 0.281 & 0.276 \\
\hline & Some College & 0.176 & 0.156 & 0.163 & 0.160 & 0.154 & 0.162 \\
\hline & College+ + & 0.169 & 0.171 & 0.187 & 0.254 & 0.198 & 0.220 \\
\hline & Missing education data & 0.083 & 0.065 & 0.061 & 0.100 & 0.094 & 0.086 \\
\hline \multirow{5}{*}{$\begin{array}{l}\text { Newborn } \\
\text { Characteristics }\end{array}$} & Boy & 0.496 & 0.509 & 0.510 & 0.482 & 0.506 & 0.510 \\
\hline & White & 0.466 & 0.473 & 0.508 & 0.615 & 0.652 & 0.681 \\
\hline & African American & 0.073 & 0.069 & 0.069 & 0.075 & 0.060 & 0.060 \\
\hline & Hispanic & 0.299 & 0.298 & 0.260 & . & . & \\
\hline & Asian & 0.091 & 0.091 & 0.091 & 0.124 & 0.098 & 0.095 \\
\hline \multirow{9}{*}{$\begin{array}{l}\text { Birth } \\
\text { Characteristics }\end{array}$} & Low birthweight (<2500g) & 0.005 & 0.048 & 0.059 & 0.029 & 0.047 & 0.061 \\
\hline & Full Term (>=37 weeks) & 0.927 & 0.909 & 0.898 & 0.915 & 0.906 & 0.896 \\
\hline & Vaginal birth after C-section & 0.035 & 0.028 & 0.022 & 0.023 & 0.021 & 0.015 \\
\hline & Forceps or vacuum & 0.077 & 0.099 & 0.083 & 0.102 & 0.092 & 0.072 \\
\hline & Less than 3 hours & 0.019 & 0.020 & 0.014 & 0.016 & 0.016 & 0.011 \\
\hline & More than 20 hours & 0.002 & 0.007 & 0.008 & 0.009 & 0.006 & 0.007 \\
\hline & Labor stimulated & 0.085 & 0.105 & 0.097 & 0.124 & 0.137 & 0.116 \\
\hline & Labor induced & 0.089 & 0.091 & 0.087 & 0.101 & 0.108 & 0.109 \\
\hline & Admitted on a weekend & 0.266 & 0.243 & 0.228 & 0.261 & 0.233 & 0.216 \\
\hline \multirow[t]{5}{*}{ Primary Payer } & Medicaid & 0.489 & 0.477 & 0.457 & 0.425 & 0.439 & 0.417 \\
\hline & Self pay/unknown & 0.038 & 0.046 & 0.045 & 0.009 & 0.031 & 0.027 \\
\hline & Private & 0.459 & 0.460 & 0.481 & 0.550 & 0.517 & 0.540 \\
\hline & Other & 0.014 & 0.016 & 0.018 & 0.016 & 0.014 & 0.016 \\
\hline & Government & 0.222 & 0.241 & 0.215 & 0.264 & 0.200 & 0.183 \\
\hline Hospital & Private nonprofit & 0.644 & 0.616 & 0.630 & 0.585 & 0.666 & 0.666 \\
\hline Characteristics & Private for-profit & 0.134 & 0.143 & 0.153 & 0.152 & 0.133 & 0.149 \\
\hline \multirow{3}{*}{$\begin{array}{l}\text { Excluded } \\
\text { Characteristics }\end{array}$} & Cesarean Section & . & . & 0.215 & . & . & 0.240 \\
\hline & & & & & & & \\
\hline & Observations & & & 3455661 & & & 2561629 \\
\hline
\end{tabular}


Figure 1: Average Length of U.S. Hospital Stay by Type of Delivery

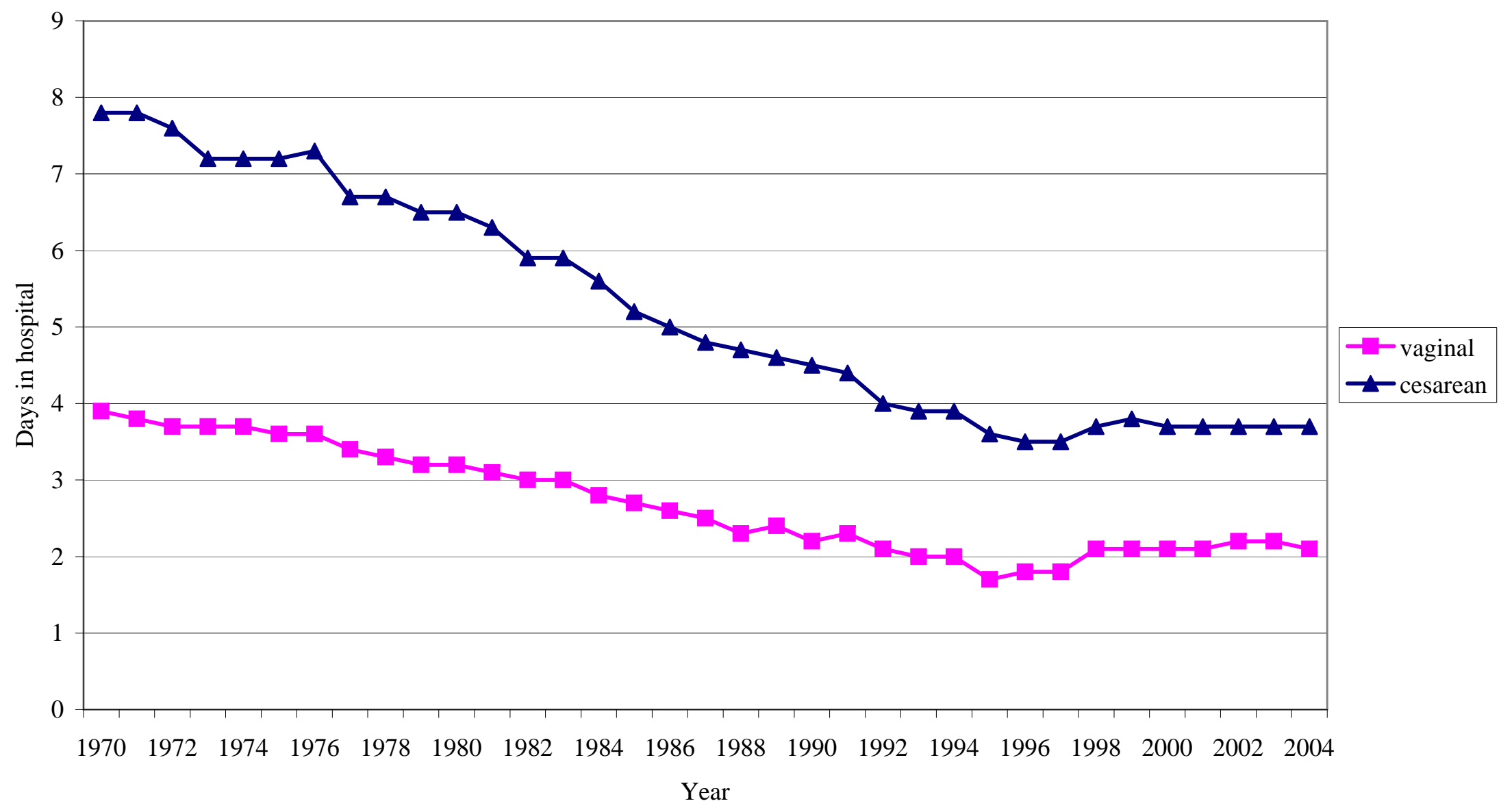


Figure 2: Vaginal Births:

Less Than 2 Days in the Hospital

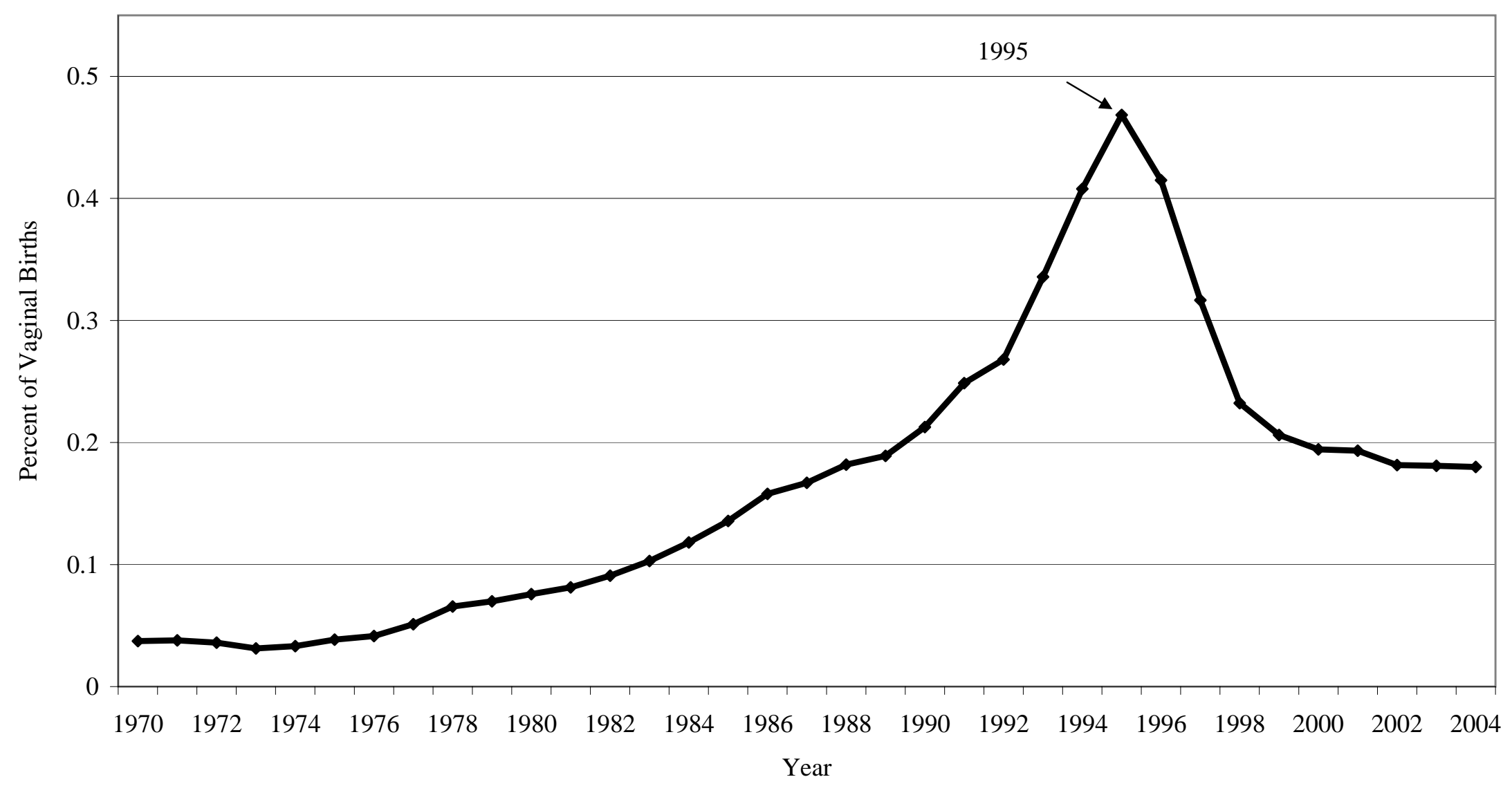


Figure 3: California Vaginal Births:

Less than 2 Days in the Hospital

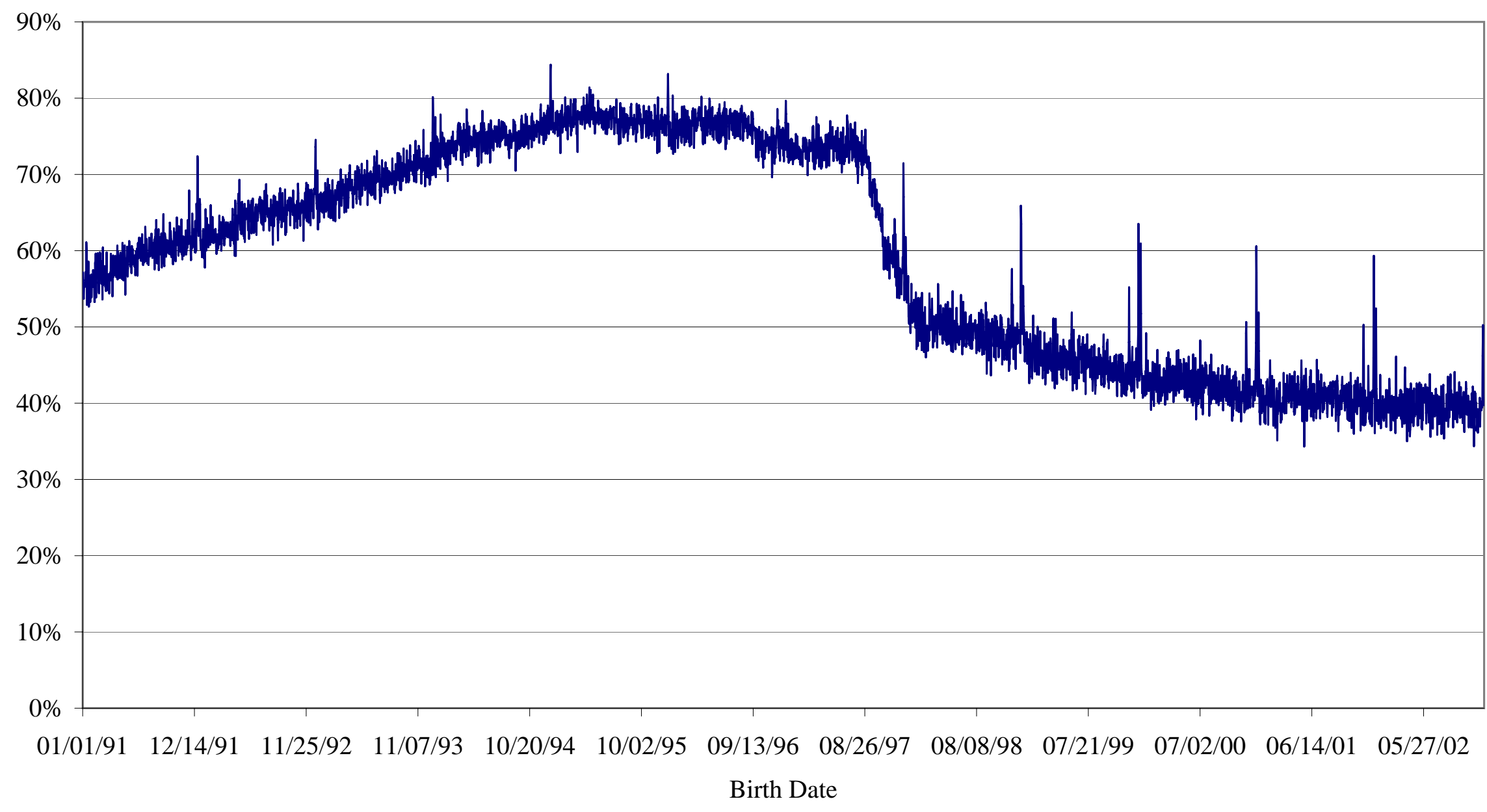




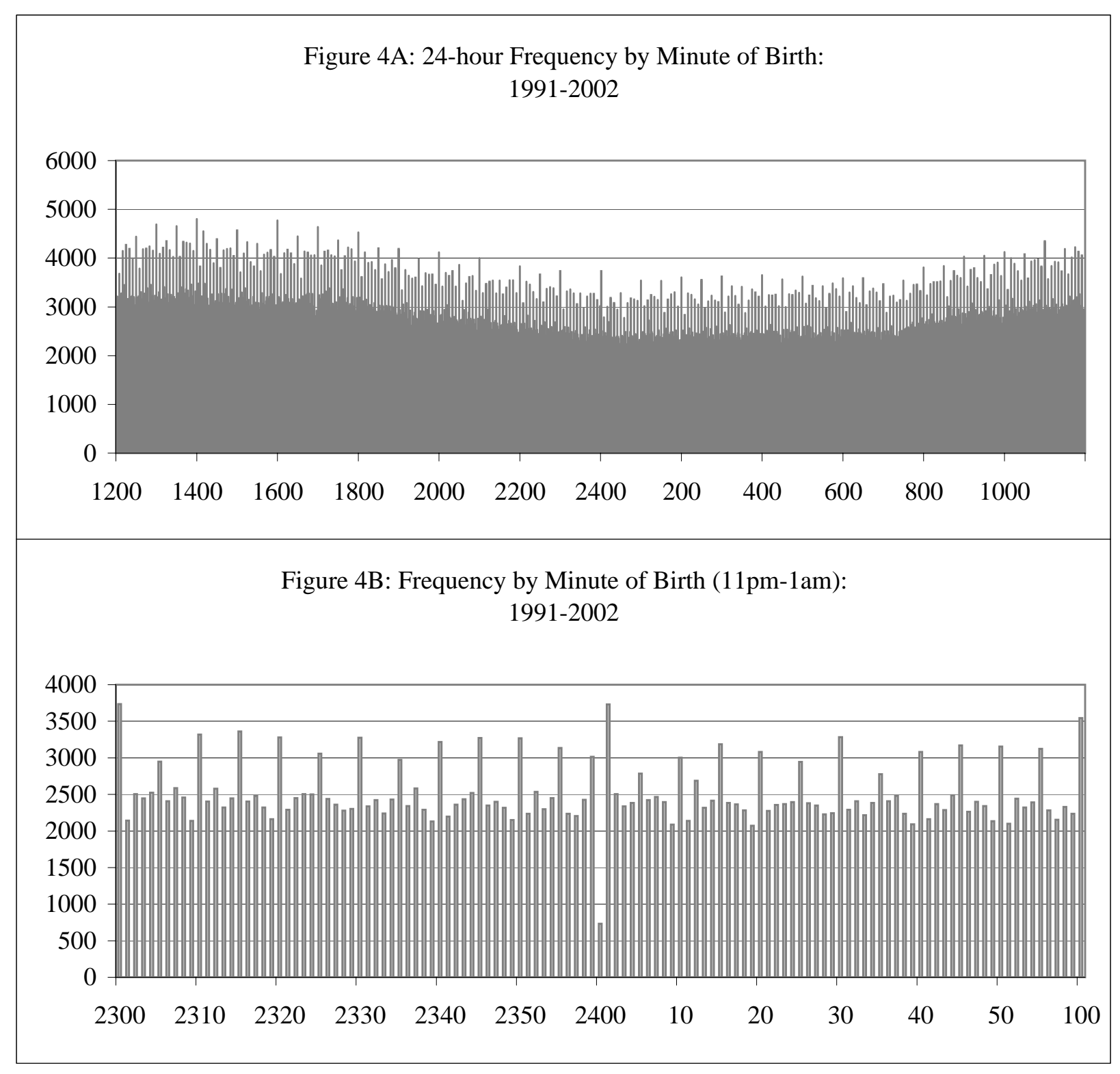




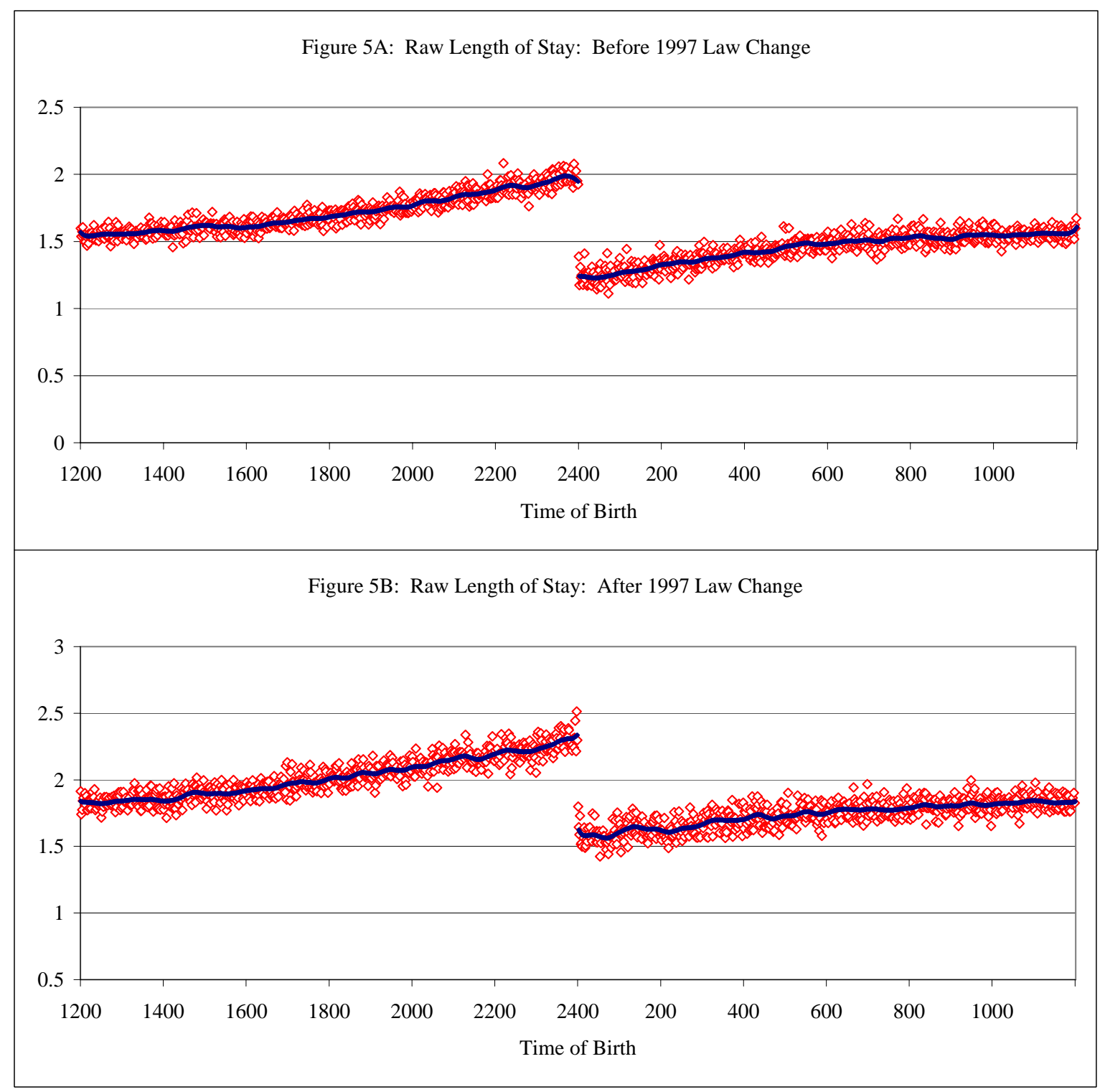

Raw length of stay is the number of midnights in care. Points represent means within 1-minute intervals from 12:00 noon to 11:59am. Lines represent local linear regressions, $\mathrm{h}=20$ 


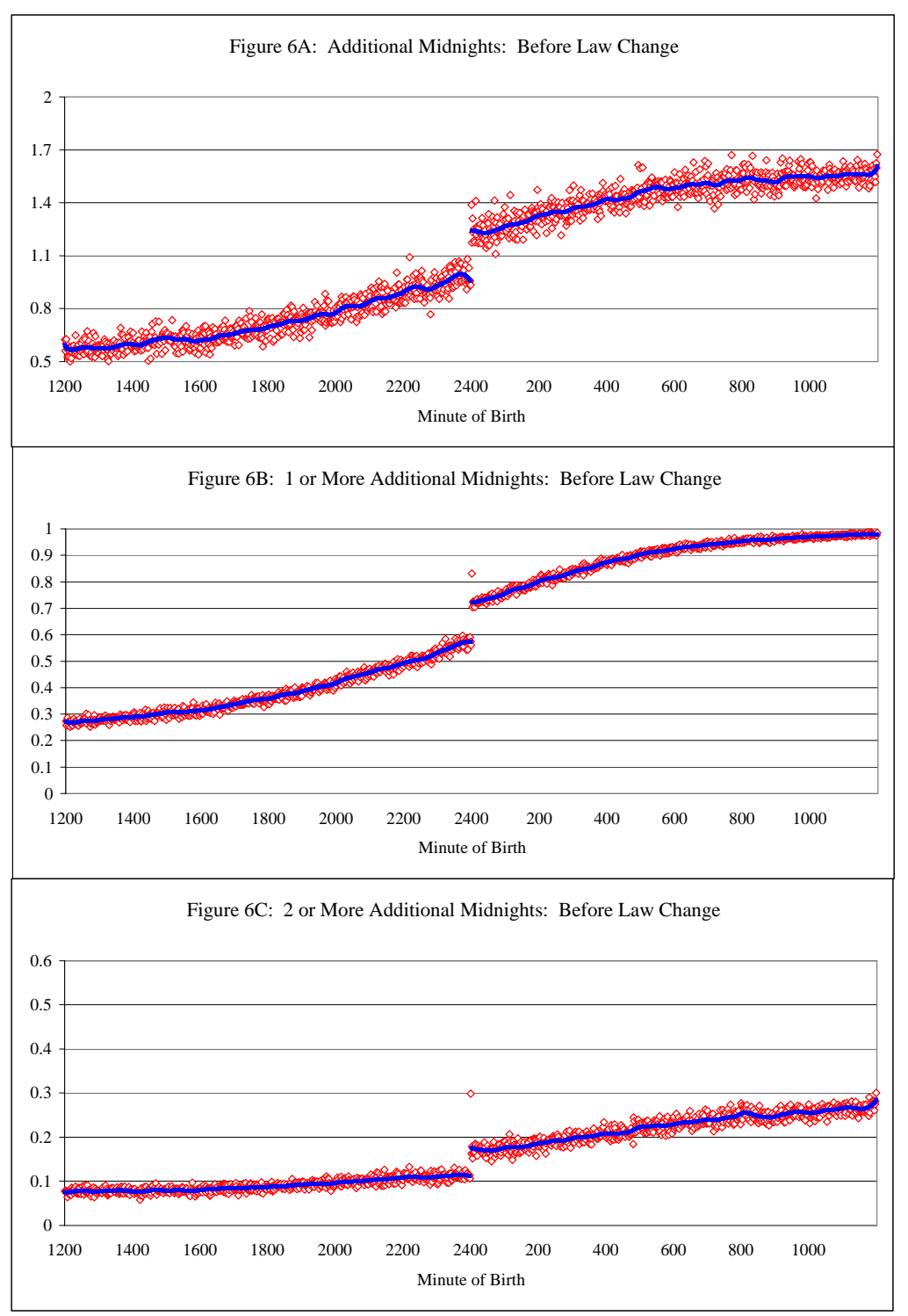

Number of additional midnights is the number of midnights for those born on or after midnight and before noon, while the number of additional midnights is measured as the number of midnights minus one for children born after noon and before regressions, h=20 


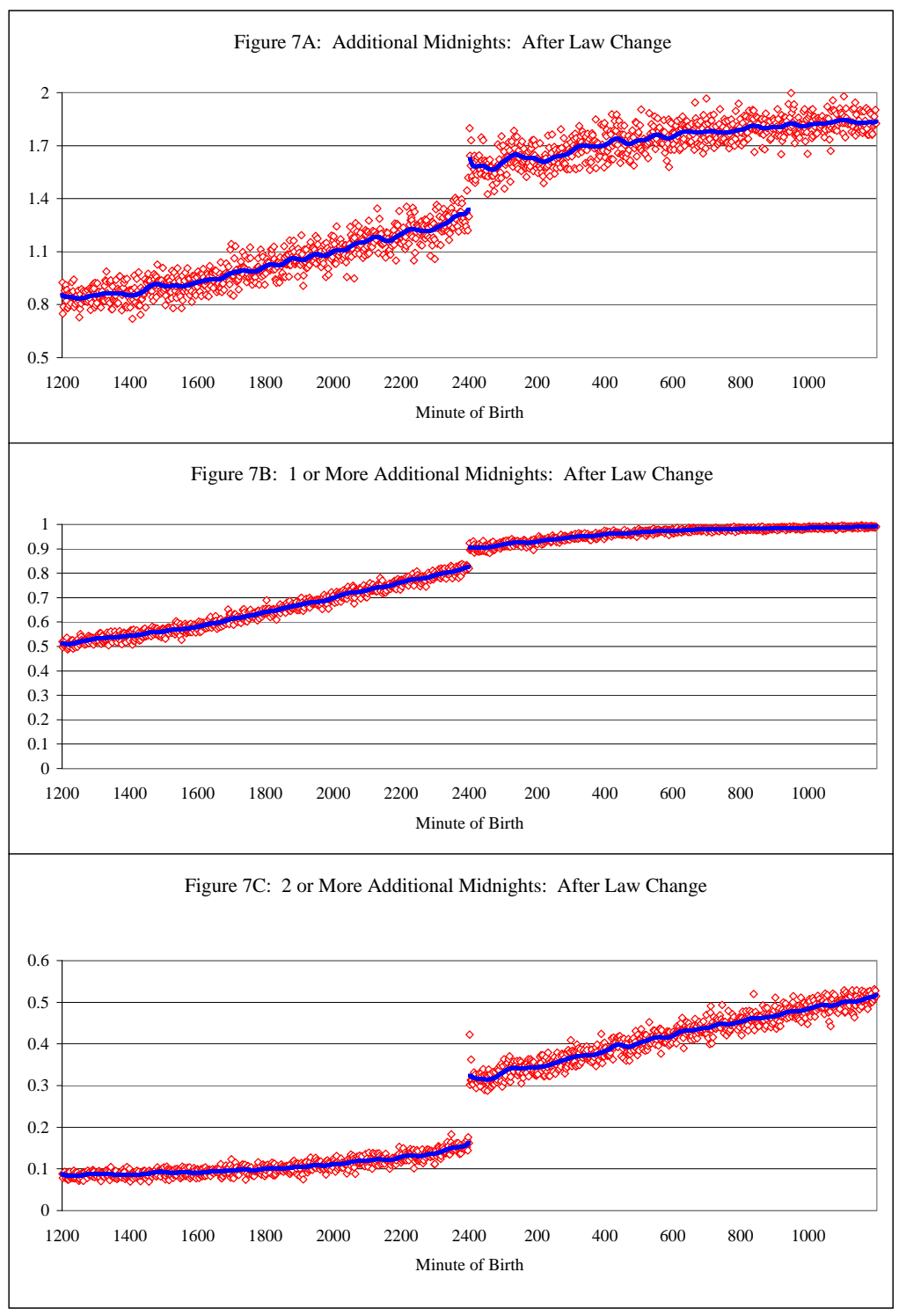

Number of additional midnights is the number of midnights for those born on or after midnight and before noon, while the number of additional midnights is measured as the number of midnights minus one for children born after noon and before midnight. Points represent means within 1-minute intervals from 12:00 noon to 11:59am. Lines represent local linear regressions, $h=20$ 


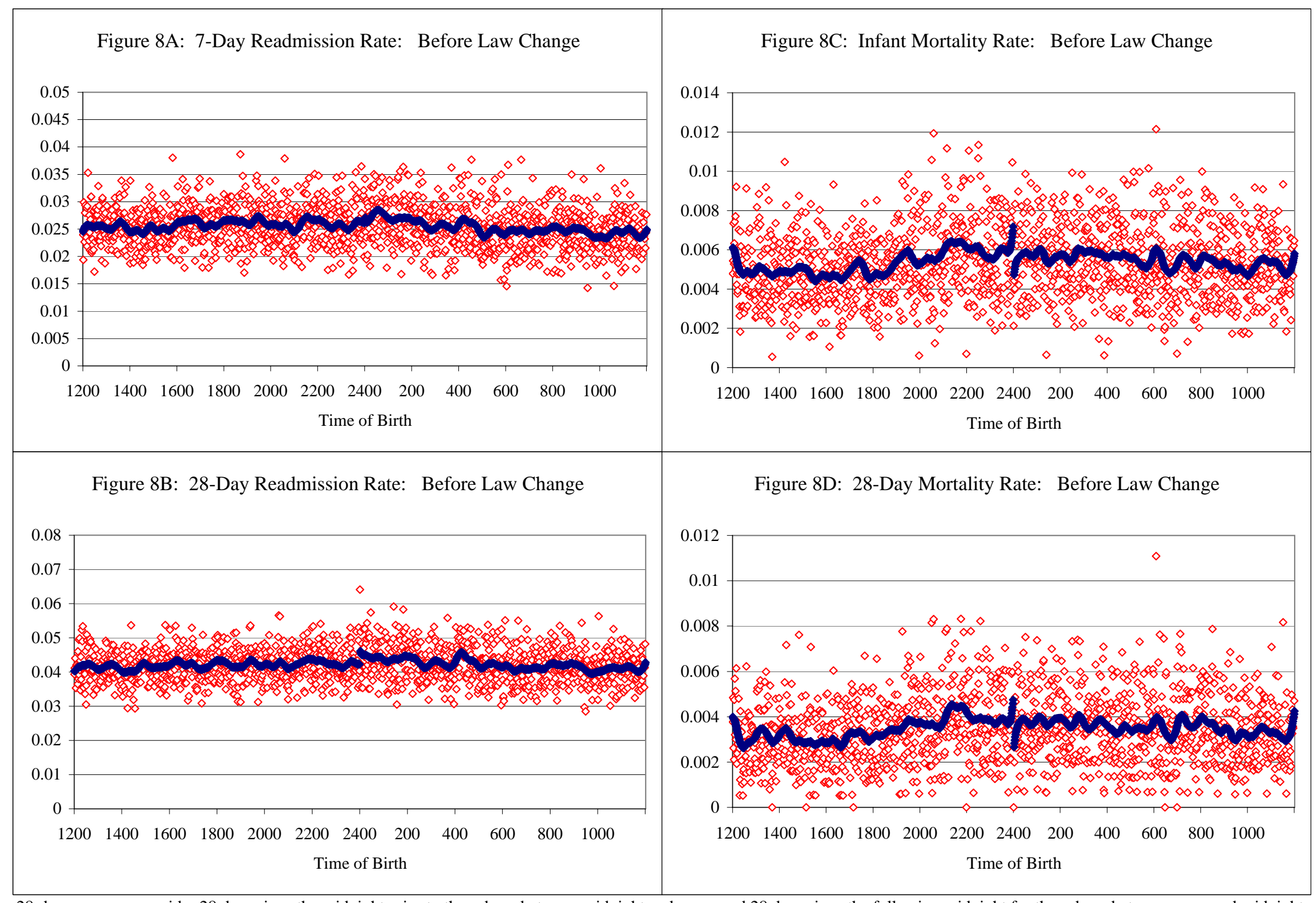

28-day measures consider 28 days since the midnight prior to those born between midnight and noon, and 28 days since the following midnight for those born between noon and midnight. An analogous consideration was made for 7-day readmissions. Points represent means within 1-minute intervals from 12:00 noon to 11:59am. Lines represent local linear regressions, $\mathrm{h}=\mathrm{Tn}$ 


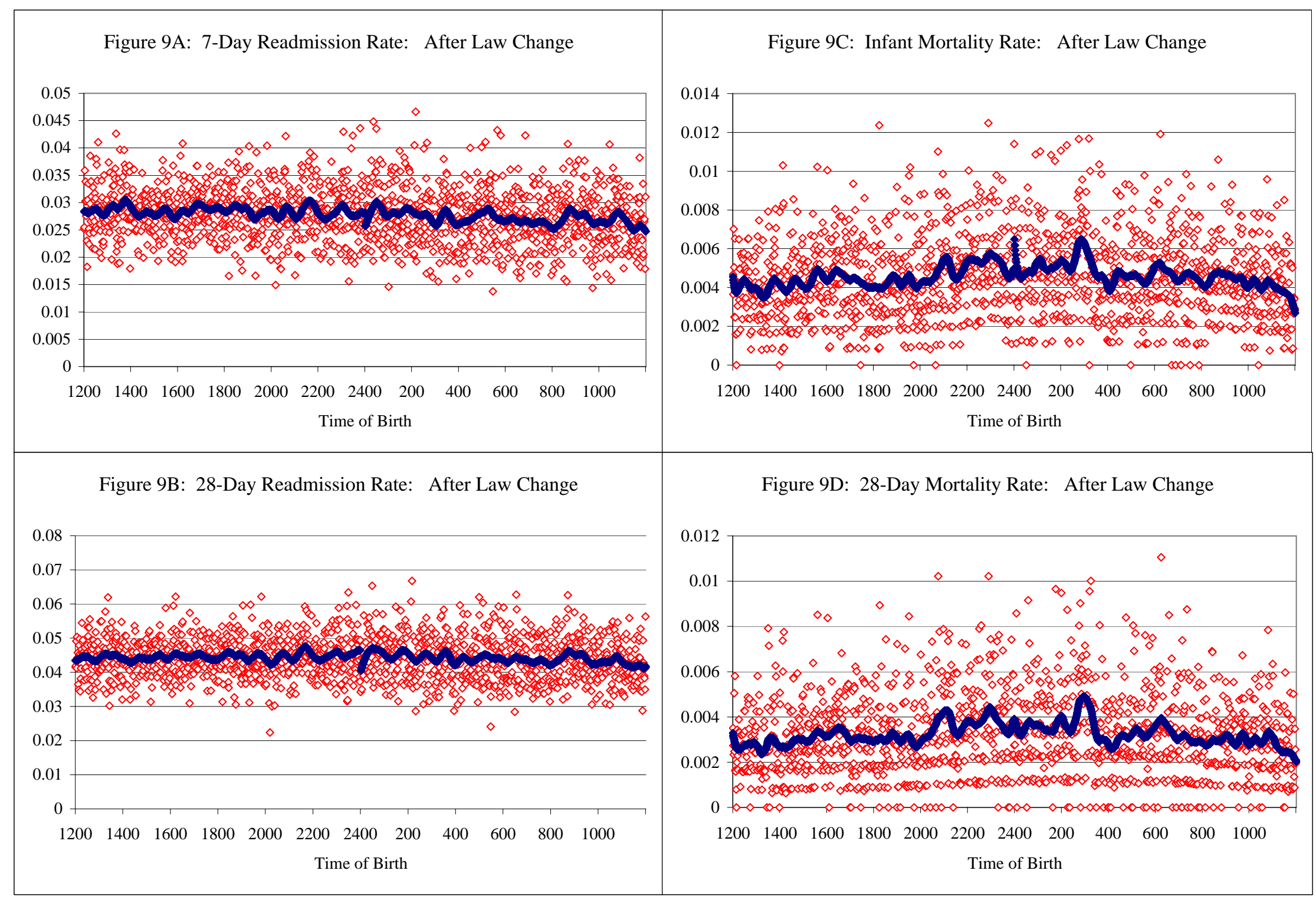

28-day measures consider 28 days since the midnight prior to those born between midnight and noon, and 28 days since the following midnight for those born between noon and midnight. An analogous consideration was made for 7-day readmissions. Points represent means within 1-minute intervals from 12:00 noon to 11:59am. Lines represent local linear regressions, $\mathrm{h}=20$ 


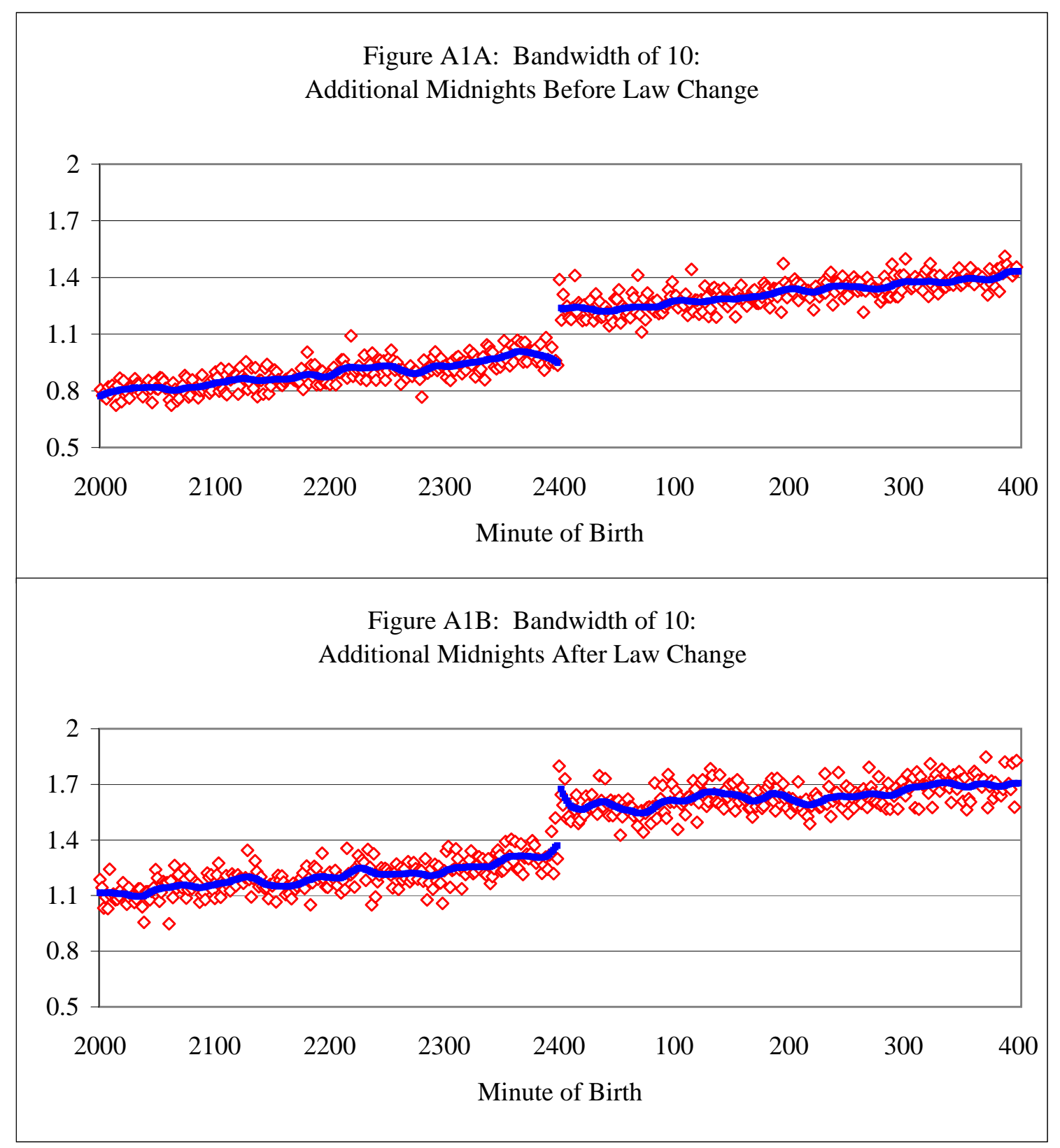




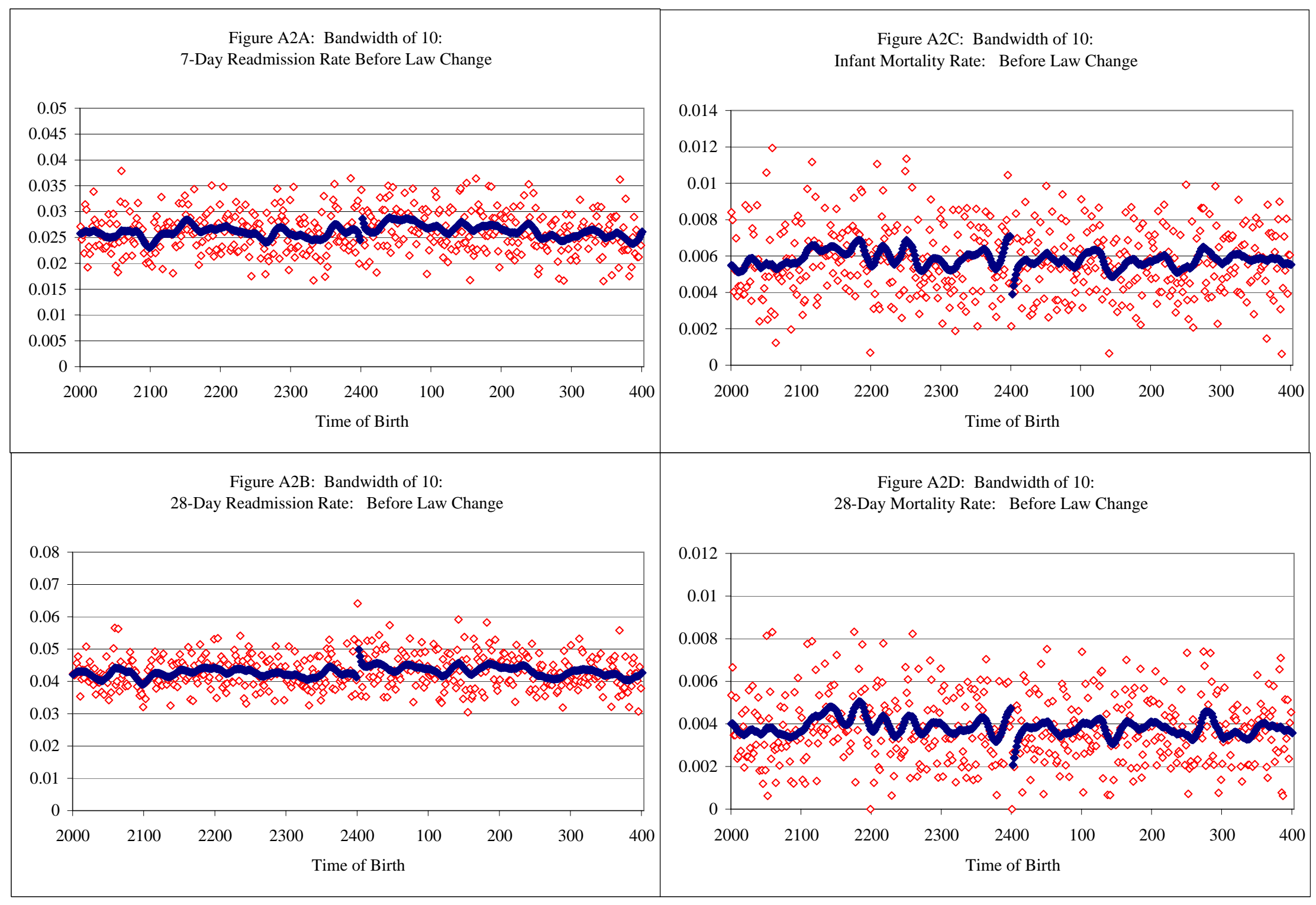




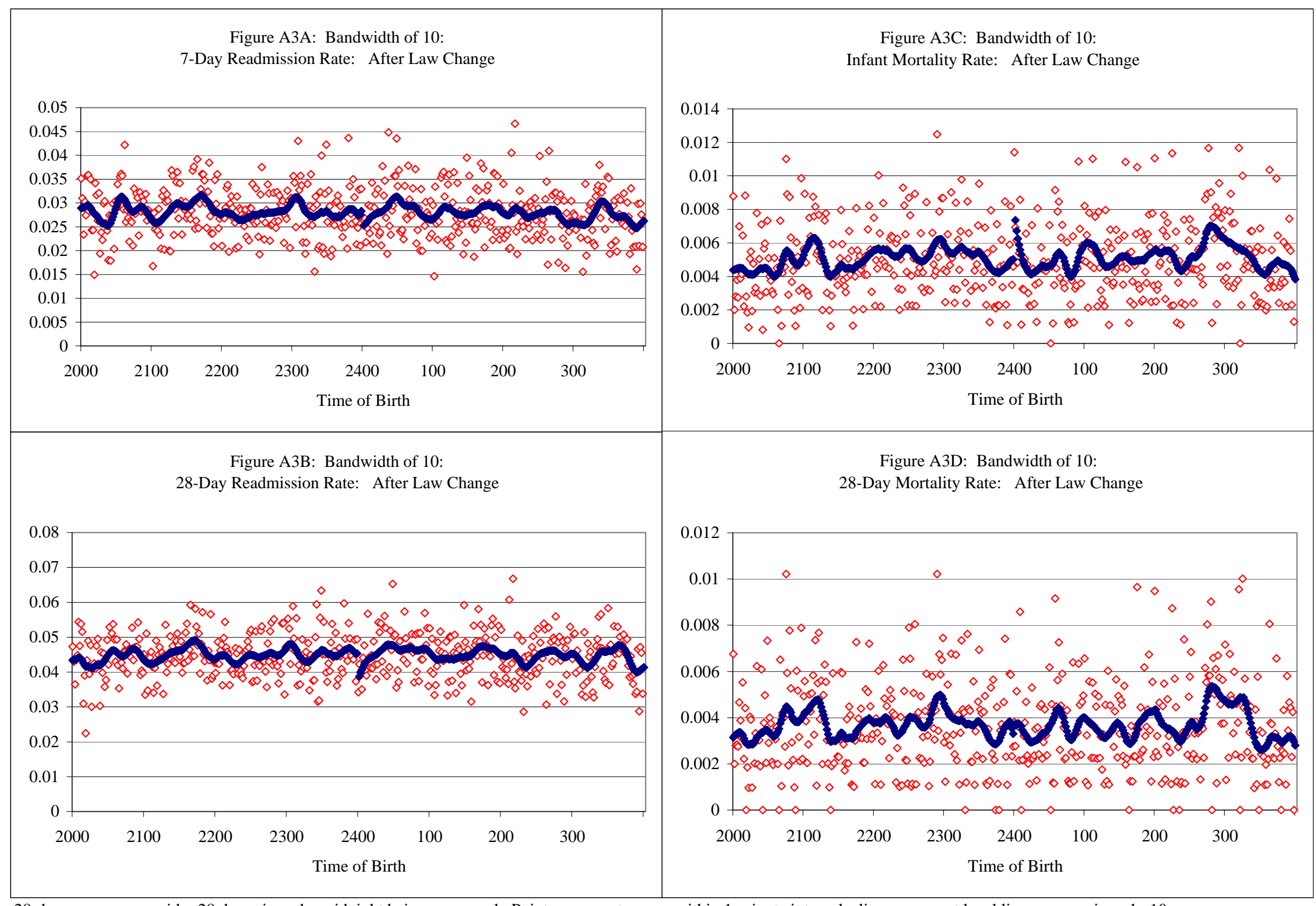

28-day measures consider 28 days since the midnight being compared. Points represent means within 1-minute intervals, lines represent local linear regressions, h=10 